\title{
Heat, Infant Mortality, and Adaptation: Evidence from India *
}

\author{
Rakesh Banerjee $^{\dagger}$ \\ Rice University \\ University of Exeter \\ Riddhi Maharaj \\ Ramakrishna Mission Vidyamandira
}

September 2019

\begin{abstract}
We examine the impact of extreme heat during pregnancy on infant mortality and check if public interventions can serve as effective adaptation strategies. We show that 2 children die as infants out of 1000 births in India for high temperature during pregnancy, tentatively due to reduced agricultural yields, wages, and greater disease prevalence like diarrhea. The heat-infant mortality relationship holds in rural India only. Using phased introduction of an employment guarantee program and partial introduction of a community health care worker program for identification, we find that only the health program is effective in modifying the temperature-infant mortality relationship in rural India.
\end{abstract}

Keywords: Adaptation, Climate Change, Infant Mortality, Temperature, Public Workfare, Community Health Workers, India

JEL Classification: Q50, Q54, Q56, Q58, I15, I18, O10

*Email all correspondence to Rakesh Banerjee at r.banerjee@exeter.ac.uk. The authors thank John Strauss, Jeff Nugent, Anant Nyshadham, Titus Galama, Yu-Wei Hsieh, Yilmaz Kocer, Jinkook Lee, Reed Walker, Alan Barreca, Tushar Bharati, Md Nazmul Ahsan, Siddharth Hari, participants at the Western Economic Association 2015, and seminar participants at the University of Southern California, University of Gothenburg, Shiv Nadar University, National Council of Applied Economic Research, Indian Institute of Technology, Kanpur and Sabanci University for helpful comments and suggestions. The authors also thank Panchajanya Banerjee, Aniruddha Ghosh and Siddharth Hari for helping with the weather, lights and agricultural data. Banerjee acknowledges funding from the University of Southern California Dissertation Fellowship, Gold Family Summer Fellowship, and Rice Academy Post Doctoral Fellowship. All errors are ours.

${ }^{\dagger}$ University of Exeter Business School, Streatham Court, Rennes Drive, Exeter, EX44PU. Email: r.banerjee@exeter.ac.uk.

*Ramakrishna Mission Vidyamandira, Belur Math, Howrah, West Bengal, Pin: 711202, India. Email: riddhimaharaj.rkm@gmail.com. 


\section{Introduction}

The predicted rise in global temperatures is likely to impact infant and child health through a variety of channels such as disease patterns, water and food insecurity, migration, and population growth (Costello, Abbas, Allen, Ball, Bell, Bellamy, Friel, Groce, Johnson, Kett, et al., 2009). This also puts children at risk globally with the most vulnerable communities being those living in poverty and having the lowest capacity to adapt (Currie and Deschênes, 2016). The reason behind lower adaptive capacity lies in poor governance, weak resource management, greater weather dependence of the economy, and weaker health infrastructures in low-income settings (Hanna and Oliva, 2016; Alexander, Carzolio, Goodin, and Vance, 2013). Except for a few studies, however, much remains to be known how societies will adapt to climate change (Barreca, Clay, Deschenes, Greenstone, and Shapiro, 2016). ${ }^{1}$ In particular, the question if public investments in better health infrastructure and income support can help moderate the effects of predicted rise in global temperatures on child health remains to be answered.

In this paper, we evaluate the effects of high temperature in utero on infant mortality and provide first large-scale evidence on the efficacy of public programs as possible adaptation strategies to high temperatures. We carry out the analysis in India because it houses around 18 percent of the world population, as per 2011 Indian census $^{2}$ and is also highly vulnerable to weather shocks (Burgess, Deschenes, Donaldson, and Greenstone, 2013). In the first part of the paper, we show that 2 children die as infants (i.e within a year of birth) out of 1000 births due to exposure to high temperature during pregnancy. The temperature effects on infant deaths are limited to rural India only and are heterogeneous across different population sub-groups. We focus on the effect of high temperatures during pregnancy on infant mortality for two reasons. First, recent "early origins" literature has demonstrated that environmental, nutritional, and several other kinds of mild shocks during pregnancy can have a significant negative effect on child health and the effects can persist even in the long run (Almond, Currie, and Duque, 2017). Second, infant mortality is often considered a good proxy measure of child health of the population (Reidpath and Allotey, 2003; Chay and Greenstone, 2000; Gonzalez and Gilleskie, 2017; Gruber, Hendren, and Townsend, 2014). Our results are robust to various tests such as alternate specifications, inclusion of mother or household fixed effects, different temperature cut-offs, and several placebo tests. Three mechanisms may explain the observed effect. First, higher temperatures could affect agricultural productivity and food prices (Deryugina and Hsiang, 2014; Deschênes and Greenstone, 2011; Burgess et al., 2013). We show that high temperatures during growing season reduce agricultural yields for a variety of major crops and depress agricultural wages. It is found that households may not be to able smooth consumption, particularly in times of aggregate weather shocks (Townsend, 1994; Santangelo, 2016). This may reduce nutritional intake and other prenatal care inputs, thus affecting fetal health (Almond and Currie, 2011; Hoynes, Schanzenbach, and Almond, 2016). Second,

\footnotetext{
${ }^{1}$ Burke and Emerick (2016) point out that a common concern with many existing impact estimates of climate change on various economic outcomes is that they do not account for longer run adjustments that economic agents might make in the face of a changing climate. These studies typically rely on short run variation in weather to estimate how outcomes respond to temperature and precipitation changes, an approach that helps solve identification problems but that might fail to capture important adjustments that agents can make in the longer run.

${ }^{2}$ http://censusindia.gov.in/2011-prov-results/data_files/india/Final_PPT_2011_ chapter3.pdf
} 
higher temperatures could have a direct physiological impact on the mother's health or have an indirect effect through increased disease prevalence like diarrhea. ${ }^{3}$ We show that high temperatures indeed lead to an increased incidence of diarrhea, cough, and fever among children. Exposure to higher temperatures can also reduce blood flow to the uterus, causing reduced fetal nutrient uptake and thus raising mortality risks among newborns (Soultanakis-Aligianni, 2003). Third, higher temperatures can increase infant mortality due to greater incidence of violence, conflict, and crime (Hsiang, Burke, and Miguel, 2013). We show that increase in temperature does not lead to increased conflict or crime against woman in our context.

The second part of the paper focuses on the possible role of a couple of public policies as modifiers of temperature-infant mortality relationship. The first policy we consider is the National Rural Employment Guarantee Act (NREGA) that provides a guarantee of 100 days of employment to rural households at a fixed minimum wage. The program was rolled out in three phases between 2006 and 2008 across districts. Both economic theory and prior empirical evidence suggest that access to NREGA employment may help households to smooth consumption in times of aggregate weather shocks (Santangelo, 2016). The second policy considered in our paper is the Accredited Social Health Activists (ASHA) Program. Following Rao (2014), we use partial introduction of ASHA in 18 high focus states in 2005 to identify its role in reducing the effects of extreme heat on infant mortality. ${ }^{4}$ Previous studies find that ASHA implementation is associated with greater vaccination (Rao, 2014) and greater institutional deliveries (Jain, Srivastava, Khan, Dhar, Manon, Adhish, and Nandan, 2008). Our data further show that ASHA implementation leads to increased use of prenatal care. We can expect that the physiological stress created by extreme heat during pregnancy can be reduced by greater access to prenatal and postnatal care, increased awareness and counseling by community health care workers. This, in turn, can be effective in reducing the effects of extreme heat during pregnancy on infant mortality. We use the spatial-temporal variation created by the phased introduction of these programs to estimate their effect in reducing the effects of higher temperatures during pregnancy. In particular, we interact exposure to these programs with exposure to heat, after controlling for district-quarter of birth fixed effects, quarter of birth-year of birth fixed effects, exposure to heat and the main effects of the programs. Our results indicate that ASHA is highly successful in reducing the heat-induced infant mortality risk during pregnancy in the last decade. We find that roll-out of ASHA is associated with a statistically significant and strong reduction in the high temperature-infant mortality relationship. We subsequently undertake a two-stage econometric approach to account and test for any possible pre-trends driving this result. The first step of this approach involves estimation of two versions of event study models while the second step involves performing a version of Quandt likelihood ratio test (Greenstone and Hanna, 2014). Here we test for a structural break in the mitigating impacts of ASHA (of heat-induced infant mortality) and assess whether the structural break occurs around the time of policy adoption. We carry out the test while controlling for differential linear pre-existing trends. In one version of the event study (where we define exposure by year of birth), we find evidence of a structural break at the time of the introduction of ASHA, thus lending validity to the earlier finding of the mitigating impacts of ASHA. However, in a more disaggregated

\footnotetext{
${ }^{3}$ Diarrhea is one of the major reasons why children under age five die around the world (Lakshminarayanan and Jayalakshmy, 2015).

${ }^{4}$ We use the terms high temperature and extreme heat interchangeably throughout the paper.
} 
version of the event study (where we define exposure by age in bins of months), we fail to find evidence of a structural break, primarily because of imprecise estimates. In our data, however, we do not find NREGA to be significantly associated with heat-induced infant mortality risk. Since both the programs were introduced at similar time frame and to some extent in similar regions, we specifically include the mitigation terms for both the programs in the same regression equation.

Reliable vital statistics data over long periods of time from all over India is difficult to obtain. So, we use the pregnancy history of mothers from multiple waves of District Level Household Survey (DLHS) to obtain child mortality records for the period of 1998-2007. We combine this data with daily-level temperature data from National Oceanic and Atmospheric Administration, aggregated at district-month level. One key empirical challenge is to disentangle the effect of season of birth from the effects of temperature as the season of birth is related to temperature as well as several unobserved parental characteristics. Several studies show that season of birth and temperature have effects on infant health and are related also to fertility and parental characteristics (Lam and Miron, 1996; Banegas, Rodriguez-Artalejo, Graciani, and De La Cruz, 2001; Buckles and Hungerman, 2013; Wilde, Apouey, Jung, et al., 2014). In this paper, we disentangle the effect of season of birth from temperature by controlling for district-quarter of birth fixed effects and quarter-year of birth fixed effects. As for temperature exposure, we use the cumulative number of degree days temperature exceeded 90 degree Fahrenheit during pregnancy in the district of birth. Following Barreca et al. (2016), we argue that the estimates are then identified from the presumably random deviations from district-quarter distribution of days exceeding 90 degree Fahrenheit after nonparametric adjustment for national deviations in that quarter-year distribution of days exceeding 90 degree Fahrenheit. In all regressions, we also control for rainfall during pregnancy. As we argue later, considering infant mortality as opposed to neonatal mortality (death within 28 days of birth) as the main outcome variable alleviates any concern regarding short-term mortality displacement or "harvesting".

The paper makes two important contributions. First, to the best of our knowledge, we provide the first evidence that basic health care provision at a large scale can serve as an effective adaptation strategy against ill-effects of climate change on child health. The existing literature mainly aims to uncover adaptation opportunities that are available in response to climate change with existing technologies. One recent study by Barreca et al. (2016) identifies air conditioning to be a central determinant of the reduction of the mortality risk associated with high temperatures during the twentieth century US. They rule out access to health care as represented by doctors per capita to be statistically related to reductions in heat-related mortality. Our analysis indicates the possible role of better health care access in mitigating health-impacts of temperature. ${ }^{5}$ In addition, we also explore the role of NREGA in mitigating the effect of climate change on infant health. A recent set of papers explores the role of public workfare programs in mitigating the effects of climate change on conflict, crime, and test scores (Iyer and Topalova, 2014; Fetzer, 2014; Garg, Jagnani, and Taraz, 2017). Dasgupta (2013) looks at the moderating effect of NREGA in response to rainfall shocks on child

\footnotetext{
${ }^{5} \mathrm{We}$ are thus able to show that adaptation possibilities are not limited to new technology adoption only. Especially in a low income country like India, the existing technology is too costly to adopt. As we show in Figure A1, less than 5 percent of rural Indian households had air-conditioning during our sample time frame. In 2012, it was still less than 6 percent. More than 50 percent of the rural households in India did not possess an electric fan during our sample period (Figure A2). These levels are similar to the US in the 1940's (Barreca et al., 2016).
} 
height, but does not explore the role of heat shocks on infant mortality. We add to this literature by exploring the role of NREGA in moderating the effect of heat on infant mortality.

Second, our finding that higher temperatures during pregnancy have important health implications for children in rural India adds to the growing body of research in economics that examines the effects of weather on several outcomes including health, mortality, and output. This literature primarily uses high frequency weather data like temperature and precipitation and exploits the plausibly exogenous variation over time to causally identify the effects. An important motivation of the literature is to estimate the costs of global climate change on different outcomes (Dell, Jones, and Olken, 2014). A recent set of studies have documented the effects of extreme temperatures on mortality, birth weight, and later-life earnings (Deschênes and Greenstone, 2011; Deschênes, Greenstone, and Guryan, 2009; Isen, Rossin-Slater, and Walker, 2015). However most studies have focused on developed countries and evidence from developing countries is relatively thin. Burgess et al. (2013) study the effect of heat on mortality in India, but they do not explore the role of high temperatures during pregnancy. Wilde et al. (2014) explore the role of temperature during pregnancy and conception in Sub-Saharan Africa and find selective fetal survival and selective fertility lead to better human capital for kids conceived during high temperatures. We rule out the channel of selective fertility in our case and argue that high temperatures during pregnancy increase infant mortality in India plausibly through biological channels and weather-induced agricultural income shocks. Thus, we extend the literature by providing further evidence of the effects of extreme heat during pregnancy on one of the most vulnerable sections of the society, namely the infants in rural India.

The available evidence on successful adaptation measures are hardly based upon a public policy (Boustan, Kahn, and Rhode, 2012; Marchiori, Maystadt, and Schumacher, 2012). Moreover, the literature on adaptation is less concerned with child health per se (Burke and Emerick, 2016; Di Falco, Veronesi, and Yesuf, 2011; Kazianga and Udry, 2006; Deschenes, 2014) and is thin with respect to developing countries (Deschênes and Greenstone, 2011; Mansur, Mendelsohn, and Morrison, 2008; Barreca et al., 2016). In this respect, our results assume special importance because it adds to the evidence by exploring the role of large scale public programs in moderating the effects of heat on child health in a large, populous and diverse developing country like India.

The paper is organized as follows. Section 2 provides the conceptual framework in which we discuss the various relationships between temperature and health including infant mortality and also the description of the public policies as modifiers to the temperature-infant mortality relationship. Section 3 discusses the data sources and relevant summary statistics. Section 4 discusses the empirical strategy for determining the temperature-infant mortality relationship. Section 5 discusses the results from fitting the model from previous section, performs various robustness checks, and explore possible drivers of the relationship. Section 6 presents the econometric models and the empirical estimates of the same to examine the extent to which public policies can modify the impacts of extreme heat on infant mortality. Section 7 concludes. 


\section{Conceptual Framework}

We review the conceptual issues and empirical evidence on the relationship between high temperatures and infant mortality in this section. Extreme heat can raise mortality for a number of reasons including physiological stress and worsening of disease environment. Additionally, heat shocks can reduce agricultural yields and hence cause real income to fall in an agricultural economy like India. This, in turn, can reduce investment in health-improving goods and adaptation instruments like electric fans, air-conditioning etc (Burgess et al., 2013). A slightly different but relevant mechanism is the increase in conflicts and crimes due to heat. For instance, Hsiang et al. (2013) find that for one standard deviation change in climate toward warmer temperatures or more extreme rainfall, the frequency of interpersonal violence rises 4 percent and the frequency of inter-group conflict rises 14 percent. We conclude the section by discussing the public policies and associated mechanisms which can reduce heat-related infant mortality.

\subsection{Temperature and Infant Mortality}

Physiological Mechanisms.- A large body of epidemiological and medical literature finds a positive nonlinear relation between higher temperatures and mortality, especially for individuals suffering from preexisting cardiovascular and respiratory diseases, elderly, pregnant mothers, and infants (Basu and Samet, 2002; Barreca et al., 2016). Failure of the thermoregulatory mechanism in the body is considered the main reason behind heat stress and heat stroke. Thermoregulation is a process in which increased heat in the human body is dissipated through greater blood flow to the skin so as to maintain a normal body temperature. Thermoregulation increases cardiac output, failure of which increases susceptibility to heat stroke. The cardiac output may fail to increase due to salt and water depletion and presence of cardiovascular diseases. Another side effect of thermoregulation is organ failure and death due to inadequate blood flow to organs-increased blood flow to the skin reduces blood flow to the intestine, leading to production of endotoxins which upon entering blood circulation causes less blood flow to organs (Bouchama and Knochel, 2002).

Pregnant mothers are particularly susceptible to high temperatures. Animal studies show that higher temperature during pregnancy causes lower birth weight, deficient formation of muscle, and reduced brain development. This happens because exposure to higher temperatures reduces blood flow to the uterus, thus leading to reduced fetal nutrient uptake and hence fetal under-nutrition (Soultanakis-Aligianni, 2003). A number of recent studies, especially in economics find that extreme temperatures during pregnancy raise chances of preterm delivery (Basu, Malig, and Ostro, 2010; Dadvand, Basagaña, Sartini, Figueras, Vrijheid, De Nazelle, Sunyer, and Nieuwenhuijsen, 2011; Andalón, Rodriguez-Castelan, Sanfelice, Azevedo, and Valderrama, 2014), lower birth weight (Deschênes et al., 2009; Andalón et al., 2014; Molina and Saldarriaga, 2016), and being classified as born not healthy (Andalón et al., 2014). ${ }^{6}$

Higher temperatures can directly affect infant health through greater disease prevalence. Diarrhea is responsible for 13 percent deaths in the under 5 year age category, killing an estimated 300,000 children in

\footnotetext{
${ }^{6}$ For instance, using data on 37.1 million births from United States, Deschênes et al. (2009) find that exposure to extreme temperature during pregnancy leads to lower birth weight. They combine their estimates with future predictions of climate change and predicts mean birth weight to reduce by 0.22 percent for whites and 0.36 percent for blacks by end of the century.
} 
India each year (Lakshminarayanan and Jayalakshmy, 2015). Recent research shows that climate change is expected to greatly increase the global burden of diarrheal diseases (Alexander et al., 2013). Usually towards the end of summer and early rainy season, bacterial diarrhea is common in India. ${ }^{7}$. It is also found that the same season also increases incidence of fever and cough, especially in the warmer and humid parts of the country. In the context of our paper, we would like to see if high temperature increases the incidence of all these diseases.

One key challenge in the literature is to disentangle the effect of season of birth from the effect of temperature. Since parents are usually found to time births relative to some specific times of year (Ahsan, 2015; Buckles and Hungerman, 2013), season of birth is associated with temperature as well as is related to several observed and unobserved parental characteristics. Several studies find that the season of birth and temperature are related to fertility and parental characteristics and have impacts on infant health (Lam and Miron, 1996; Banegas et al., 2001; Ahsan, 2015; Buckles and Hungerman, 2013; Wilde et al., 2014). Apart from accounting for non-linear impacts of temperature, many studies in the economics literature on the effects of temperature in utero on health and other outcomes carefully control for geographic fixed effects or geography-season specific fixed effects to control for unobservables related to both temperature and birth outcomes. In the current paper also, we allow for non-parametric specification for the effects of extreme heat on infant mortality and disentangle the effect of season of birth from temperature by controlling for district-quarter of birth fixed effects. This corrects for any unobserved district-specific seasonal factors which can affect health and mortality of the newborn.

Income Mechanisms.- Unlike in the advanced economies, India has high dependence on agriculture for both employment and production. Burgess et al. (2013) find that extreme heat in the post-monsoon growing season limit the formation of grains in key crops such as rice and wheat. This negatively affects the sizes of harvest and accentuates income downturns for those dependent on agriculture in India. Moreover, malnutrition and morbidity are the highest during this time for a number of reasons- food stocks are depleted, demand for labor and agricultural wages are low, and food prices are high. Thus a large income shock can be especially damaging for pregnant mothers and newborns. ${ }^{8}$ On the contrary, because of limited seasonality in income and nutritional status (i.e less exposure to weather-induced income shocks), pregnant mothers and little children in urban centers are less prone to extreme heat events. We explore both these possibilities in this paper. ${ }^{9}$

Effect through Conflict and Crime.- One of the leading mechanisms through which high temperatures can increase mortality is through an increased incidence of crime and conflict. There exist both biological and non-biological mechanisms that can explain this phenomenon. On the biological side, high temperature influences impulsivity and aggression by affecting serotonin-neurotransmission in the brain. This makes people prone to greater aggression and violent crimes (Dell et al., 2014). Non-biological mechanisms include heat-induced lower opportunity cost of violence or protests, reduced state capacity to maintain security for the associated lower economic growth, higher food prices leading to food riots, and weather-

\footnotetext{
${ }^{7}$ https://www.nhp.gov.in/Seasonal-Diarrhoea_mtl

${ }^{8} \mathrm{~A}$ cross-country study in Africa finds that high temperature-induced drought, which is likely to predict poor or delayed harvests and hence maternal malnutrition, leads to higher infant mortality in arid areas (Dell et al., 2014).

${ }^{9}$ For a detailed literature review on the impact of weather on income. the readers can refer to Dell et al. (2014).
} 
induced migration (Dell et al., 2014). It is found that civil conflicts increase nearly fifty percent of the mean in Africa for each degree Celsius increase in temperature (Dell et al., 2014). Moreover, a number of studies based in the US find that warmer temperature is positively associated with aggravated assaults, horn honking, property crime and criminal activity (Dell et al., 2014). Although we are not aware of any study which analyzes the impact of extreme heat on violence or conflict in India, there is evidence that HinduMuslim riots go up if there are negative rainfall shocks (Bohlken and Sergenti, 2010). Another study by Sekhri and Storeygard (2014) finds that murder of women for failing to bring sufficient dowry is higher in India in recent years during periods of low rainfall. In a similar vein, we explore in the paper if India faces more crimes against women and a greater incidence of conflicts involving left-wing insurgency, Islamic terrorism, armed terrorist movements, and the like when the temperature is high. A significant association will point towards another mechanism in which extreme heat affects infant mortality.

\subsection{Adaptation to High Temperature}

Following our conceptual framework, we explore two public policies in India that can possibly modify the temperature-infant mortality relationship for our sample time frame. One of them is a national employment and public works program and another is a community health worker program in villages. While community workers can influence infant mortality due to heat more directly by mitigating health impacts as they happen, the employment guarantee program can affect the same through smoothing consumption. Since these programs were introduced gradually across the country, we utilize the associated spatial by temporal variations in our identification of the program effects. We discuss below how each of these adaptation channels can help mitigate the impacts of temperature on infant mortality.

National Rural Employment Guarantee Act (NREGA).- Temperature fluctuations and weather shocks are found to have large effect on income in developing countries, where large proportions of the work force are employed in the agricultural sector (Burgess et al., 2013). Moreover, in a country like India, access to credit is often limited in times of aggregate weather shocks so that individuals cannot smooth consumption perfectly (Rosenzweig and Wolpin, 1993; Rose, 1999; Townsend, 1994). The passing of National Rural Employment Guarantee Act (NREGA) was introduced mostly to address this problem. It was passed by the Government of India in 2005. The main purpose of the act is to provide a legal guarantee of 100 days of employment to every rural household at a fixed minimum wage. The act stipulates the wage to be the same for both males and females and at least one third of the employment must go towards females. The household is required to apply for a job card with the local village council and is typically expected to provide manual labor on projects like road construction, earthwork on irrigation canal, or other maintenance work. The local village council is responsible for processing and issuing the job card. The government is mandated to provide employment within 15 days of application, failing which it has to provide unemployment insurance. The central government bears the entire cost of labor and 75 percent of the material costs while state government bears the rest (Shah and Steinberg, 2017). A public workfare program like NREGA has several advantages. Since those who are willing to work at the minimum wage are only likely to apply, it will self-select people into the program. 
NREGA increases labor demand which is also likely to increase private sector wages (Imbert and Papp, 2015). Particularly, in times of low demand for labor, NREGA is likely to provide a guarantee of employment and hence smooth consumption (Klonner and Oldiges, 2014). In our context, NREGA could be a coping mechanism if extreme temperature can affect fetal health through reduced income, arising from weather-induced shocks to employment and agricultural production. Moreover, NREGA can provide extra income which can be used to make preventive or curative health investments against high temperatures. For instance, it can be used to make durable investments like an electric fan which may moderate the effect of heat. ${ }^{10}$ A study by Burgess et al. (2013), in fact, finds that the expansion of bank branches in rural India mitigates the effect of high temperatures on mortality through greater availability of credit. ${ }^{11}$

NREGA was introduced in a phased manner. The act was passed in 2005 and 200 districts got access to the program in February 2006. In April 2007, 130 districts were added, and the remaining districts got access in 2008. The explicit goal of the phased roll out was to target the poorer districts first. It also guaranteed that each state would have atleast one district in the first phase of the program. We use this phased roll out to identify the effects of NREGA in reducing the impacts of extreme temperature on infant mortality.

Accredited Social Health Activists (ASHA).- One of the primary goals for public health policy in developing countries is to expand access to the formal health care sector (Adhvaryu and Nyshadham, 2015). In our context, access to better health care could mitigate the heat-related ailments for pregnant mothers and newborns in two ways: first, by treating heat-related health complications; and second, by raising health capital to tolerate extreme heat stress (Barreca et al., 2016). Community health workers are particularly responsible for the health of mothers and babies in a rural community and could play a major role to protect them from heat-related health problems. Since weather and environmental factors strongly influence health care access (Adhvaryu and Nyshadham, 2015), community health workers have a lot of potential in this domain because of their proactive role in bringing formal health care to the doorsteps of beneficiaries. ${ }^{12}$ As we show later, community health workers have indeed been quite successful in reducing heat-induced infant mortality in rural India, which is also a novel contribution of our paper.

The health care set up in rural India is three-tiered, with health Sub Centers (SCs) at the primary level, followed by Primary Health Centers (PHC), Community Health Centers (CHC), and district hospitals. Health SCs are single room facilities run by Auxiliary Nurse Midwife (ANM) who is responsible for a population of 4,500 individuals. The ANM worker caters to too many individuals to provide regular home visits. Thus it was necessary to have community health workers for providing the necessary bridge between

\footnotetext{
${ }^{10}$ Khanna and Zimmermann (2014) argue that NREGA may actually increase the incidence of conflicts (and hence, in our context, greater infant mortality) in the short run that is driven by police-initiated attacks, and an increase in the number of captured Maoists. The authors hypothesize that such anti-poverty programs can increase the effectiveness of the government forces by improving the relationship between citizens and the state. This makes the civilians more willing to share information on insurgents. However, our subsequent results indicate that this mechanism may not be strong in mitigating all of NREGA's impacts in reducing heat-induced infant mortality.

${ }^{11}$ Evidence of adaptation on labor productivity in India is reported by Adhvaryu, Kala, and Nyshadham (2014). They show that the introduction of LED lights in garments factories in India reduces the temperature on factory floors which raises productivity, particularly in hot days.

${ }^{12}$ On the contrary, Barreca et al. (2016) report that access to health care as represented by doctors per capita, is not statistically related to reductions in heat-related mortality in the US.
} 
the health care system and households (Rao, 2014). In 2005, the Government of India introduced a community health worker program, called Accredited Social Health Activists (ASHA), with a particular focus on 18 states in India. ${ }^{13}$ The 18 high focus states are Uttar Pradesh, Bihar, Rajasthan, Madhya Pradesh, Orissa, Uttaranchal, Jharkhand, Chhattisgarh, Assam, Sikkim, Arunachal Pradesh, Manipur, Meghalaya, Tripura, Nagaland, Mizoram, Himachal Pradesh, and Jammu and Kashmir. ${ }^{14}$ After 2009 (which is outside our sampling frame), the program was heavily implemented in other parts of India as well. ASHA is one of the key strategies of National Rural Health Mission (NRHM) of Government of India. ${ }^{15}$ Some of the primary responsibilities of an ASHA worker include paying regular visits plus registering and accompanying pregnant mothers to the local health facility. They are also tasked with counselling women on needs of immunization, organize and mobilize people for immunization camps, spread general awareness about health, sanitation, and nutrition (MOHFW, 2009). The prescribed policy of the Government of India requires ASHA workers to be educated, with at least upto $8^{\text {th }}$ standard, and should belong to the age group of 25 to 40 years. They are also required to receive training in the sub center. The ASHA worker is not a paid worker and receives small sums of money for each task performed. ${ }^{16}$

ASHA workers have been shown to be effective in improving maternal and child care. As we show later, ASHA is associated with increased use of antenatal care services. Jain et al. (2008) find that 70 percent of institutional deliveries conducted are motivated by ASHA in Uttar Pradesh, a state in North India. Rao (2014) uses the partial introduction of ASHA till 2008 and finds that ASHA implementation is associated with increased vaccination coverage. Randomized evaluations of such home visit programs in the US have been found to reduce infant mortality by reducing postneonatal deaths (Chen, Oster, and Williams, 2016).

We can think of several mechanisms through which an ASHA worker can help reduce heat-related infant mortality. Because of their training and better information about heath care services at different facilities, the workers can escort and arrange for immediate and appropriate care of a person suffering from heat stroke. ASHA workers usually carry Oral Rehydration Solution (ORS) and other appropriate drugs for treating heat-induced diarrhea, nausea, and vomiting. Since refrigerators are not common in rural parts, stored cooked food is likely to get spoiled in extreme heat. ASHA workers can advise households not to store cooked food to avoid these heat-induced diseases. Also, ASHA workers are trained to identify danger signs during pregnancy (including high blood pressure) and take appropriate action. ASHA workers can also be effective in communicating the needs of a village to higher authorities. During episodes of high temperatures, for instance, they can request for additional antenatal care camps at multiple locations so that pregnant women do not have to walk long distances. More importantly, as we will show later,

\footnotetext{
${ }^{13}$ Community health care workers and trained local midwifes have been successful in many parts of the world in providing maternal care. Government of India introduced a community health care worker program way back in 1977 . These health care workers, later came to be known as Village Health Guides, were mostly males whose main targets were males for family planning programs. This program was not very successful and was later discontinued (Bhowmick, 2016). In the recent years, there is a renewed interest in community health care workers, especially for remote rural locations where it is hard to have trained doctors and nurses.

${ }^{14}$ https://www.nhm.gov.in/images/pdf/about-nrhm/nrhm-framework-implementation/ nrhm-framework-latest.pdf

${ }^{15}$ Though there were several other policies of NRHM apart from ASHA, Rao (2014) shows that high focus states and non-high focus states had similar access to other programs under NRHM, except ASHA.

${ }^{16}$ For more details about the ASHA program, the readers may refer to Rao (2014) and Bhowmick (2016).
} 
implementation of ASHA is associated with greater antenatal care and iron supplementation. In India, attending prenatal care is correlated with a 27 percent decrease in the probability of neonatal mortality (Bharadwaj and Lakdawala, 2013).

Similar to Rao (2014), we use the partial introduction of ASHA upto 2008 to identify its role in reducing the effects of extreme heat on infant mortality. In our context, it is expected that the physiological stress created by extreme heat during pregnancy can be reduced by better access to prenatal care, increased awareness and counseling by community health care workers. Thus, ASHA workers can be effective in reducing the effects of extreme heat during pregnancy on infant mortality.

\section{Data}

We explore the relationship between temperature and infant mortality by combining a number of different datasets. We use microdata on mortality and individual characteristics, along with temperature and rainfall data, complemented with nightlight data for our central analysis. For mechanisms and adaptation, we additionally consider data on agricultural yields, separate datasets on crime and conflicts, and district-level program implementation schedules. In this section, we describe all these data sources and present some basic summary statistics.

\subsection{Infant Mortality Data}

This paper uses data from the second and third waves of the District Level Household Survey, known as DLHS 2 and DLHS 3 respectively. ${ }^{17}$ DLHS 2 was conducted by the International Institute of Population Sciences (IIPS), Mumbai between 2002 and 2004 across 504 Districts in India. It surveyed 620, 107 households and 507, 622 married women across India. Similarly, DLHS 3 was conducted by IIPS, Mumbai between 2007-2008 across 601 districts in India and collected data from 720,320 households and 643, 944 ever married woman. The main focus of the survey was reproductive health of woman, while it also collected information on general household characteristics. We combine DLHS 2 and DLHS 3 and use pregnancy history of married woman to create death and birth records of born children. We limit the recall period to a maximum of 7 years to limit recall bias. ${ }^{18}$ Unfortunately, we do not have information on the district of birth of an infant so that we proxy the location of birth of the child with the district in which the mother is interviewed. Though we do not have data on migration in the survey, we believe the district of interview is a good proxy for district of birth because of our consideration of a limited recall period. As several new districts were created by the time DLHS 3 was conducted, we map the new districts into their corresponding old districts. Some new districts were carved out from two or more districts- we drop them altogether from

\footnotetext{
${ }^{17}$ We don't consider the first wave of the survey as the parental background could not be ascertained for the infants. We discuss later that parental background can be crucial in our analysis to control for any possible selective fertility.

${ }^{18}$ DLHS 2 was partly conducted in 2002 and for the remaining districts it was conducted in 2004 . We take a 5 year recall period for those districts, where interviews were conducted in 2002. For the remaining districts (interviewed in 2004) we have used a 7 year recall period to have a continuous sample from all districts from 1998. For DLHS 3, the recall is restricted to a maximum of 4 years as the pregnancy information is collected for births since 2004 .
} 
the analysis because of the assignment problem. ${ }^{19}$ Our final analysis covers 567 districts from 27 states and the Union Territories of Delhi and Chandigarh. ${ }^{20}$ The survey also provides information on several parental characteristics which we use as control variables in regressions. One limitation of the data is that the cause of death for infants is unavailable; this limits the scope to directly examine the relationship between temperature and causes of death that are plausibly related (and/or unrelated) to high temperatures. However, DLHS 3 collected information if the two youngest children in a family, born after 2004, suffered from Diarrhea, cough, or fever within two weeks of survey. We use this information to suggest if these illnesses could be causing deaths among infants due to heat.

\subsection{Temperature Data}

This paper uses NCEP/NCAR Reanalysis 1 daily temperature data from National Oceanic and Atmospheric Administration (NOAA). ${ }^{21}$ The data is available as daily mean from 1948 till present over a $2.5 \mathrm{X} 2.5$ latitude-longitude global grid. Following the literature, we aggregate the grid-level data to the district level by taking an inverse-distance weighted average of all the measurements from the grids that are located within 250-kilometer radius of each district's latitude-longitude so that the closer grids receive greater weight. $^{22}$ Although weather station data is available in India, non-exogenous placement of weather stations introduces a lot of bias in the data, making it unsuitable for causal studies. For example, weather stations might be placed in less remote areas and the consequent measurement error in extrapolating the data from these stations across space might create non-classical measurement error in the explanatory variables including temperature. Moreover, the data from the weather stations are not consistently available over time, creating a problem of missing data. Re-analysis data combine data from several sources and combine it with global climate models to produce consistent estimates over time and space. Thus re-analysis data has the advantage that it is available uniformly over time and space. The measurement error in that case will not be related to district level characteristics. For these advantages, re-analysis data is been increasingly used in the economics literature (Burgess et al., 2013).

\subsection{Rainfall Data}

This paper uses monthly mean rainfall data from Center for Climatic Research, University of Delaware. ${ }^{23}$ The data contains mean monthly rainfall at a 0.5 X 0.5 latitude longitude grid, from 1900 to 2010 . We

\footnotetext{
${ }^{19} \mathrm{We}$ do not have information on night time lights for Delhi and Mumbai. In the regressions with lights as controls, we have omitted these districts too.

${ }^{20}$ DLHS 3 does not cover Nagaland, so we usually omit Nagaland from our analyses.

${ }^{21}$ The following link provides more details on the temperature dataset: http://www.esrl.noaa.gov/psd/data/ gridded/data.ncep.reanalysis.surface.html

${ }^{22}$ We have obtained the latitude-longitude for the districts from google. The reason we could not use precise district centroids is due to unavailability of a shape-file that corresponds to the district boundaries used in DLHS 3. However, as a robustness check, we calculate the district centroid and match with the district boundaries in DLHS 3 from a shape-file available from https : / /gadm.org/. We do not obtain a perfect match for all the districts. However our main results are almost identical if we limit the sample to the matched districts only and use the coordinates of the centroid (not shown).

${ }^{23}$ The following link provides more details: http://climate.geog.udel.edu/ climate/html_pages/ Global2011/Precip_revised_3.02/README.GlobalTsP2011.html
} 
follow the same procedure to aggregate the grid-level rainfall data at district level as for aggregating temperature data. Following the literature, we control for rainfall in our regressions as rainfall is correlated both with temperature and infant mortality in India. ${ }^{24}$ On the one hand, most rainfall takes place in India when the temperatures are high. On the other hand, rainfall, along with high temperature worsens the disease environment and leads to greater incidence of malaria and diarrhea. However, better rainfall can also improve infant health status in rural areas through greater income and nutrition availability.

We summarize the infant mortality rates and weather variables for our sample in Table 1 . To highlight the spatial differences, we report the mean levels of the variables separately for the rural and the urban areas. During the period 1998-2007, 76 percent of the sample comes from the rural areas, with an infant mortality rate of 54 per 1, 000 live births. The rates are significantly less at 43 infant deaths per 1, 000 live births in the urban areas. Both these rates are around $7-8$ times higher than the national average in the US (Chen et al., 2016). We also report the average number of days in the birth month of a child when temperature exceeds 90 Degrees Fahrenheit-it is slightly greater than 2 for both the rural and the urban areas. These rates are at par with the hot parts of the US, that is Western and Southern regions of the US and way above the national average of the US (Barreca et al., 2016). The mean precipitation levels during pregnancy for the rural areas are greater at 100 millimeters as opposed to 95 millimeters in the urban areas.

We also provide a demographic comparison of newborns and their parents by rural and urban regions. The boy to girl ratio is almost same across the two regions at 52 percent. Mothers in urban areas receive nearly double the years of schooling (6 years) relative to the mothers in the rural areas ( 3 years). This can be one of the reasons why infant mortality is less in the urban centers. However, the average age of mothers in our sample is constant at 27 years in both the rural and the urban areas. As far as the religion of the household head is concerned, Hindus constitute more than 70 percent of the entire sample, with more Hindus living in a village than in a city. While only 12 percent of the households are Muslims in rural areas, the share goes up to 21 percent in urban areas. Christians and other minor religions are more or less evenly distributed across rural and urban areas and constitute close to 10 percent of the entire population.

\subsection{Other Data Sources}

Agricultural Yields.- We use data on agricultural yields from the Directorate of Economics and Statistics, Ministry of Agriculture, Government of India. This data contains information on agricultural yields, production, and area cropped for each crop and season from 1998-2010. We construct a district-level panel on agricultural output for each crop and season from this dataset. In this paper, we choose 6 major summer crops, also known as Kharif as these are most likely to be affected by extreme heat. Kharif cropping starts in May and ends in October. The six major crops we consider are 5 food crops such as rice, bajra, soybean, groundnut and jowar, and one cash crop, cotton.

Conflict and Crime.- For conflict and violence, we use the data collected by the South Asian Terrorism Portal (SATP) which is a database of terrorist incidents from newspaper reports. The database also provides

\footnotetext{
${ }^{24}$ We also have data on relative humidity. However, we chose not to include relative humidity because relative humidity is mechanically related to temperature (Barreca (2012)).
} 
information on the district and date of the incident. ${ }^{25}$ Incidents of terrorism (or armed conflict) in India emanate from several sources. First, a significant number of incidents are left-wing insurgency related violence. This is primarily concentrated in and around the poorer districts of Central India. Another source of violence is from the separatist movements, primarily concentrated in the North-Eastern states of India and Punjab. ${ }^{26}$ A third and less frequent source of violence are incidents related to Islamic terrorism. We use keywords in the newspaper reports to classify incidents as related to left-wing, separatist, or Islamic terrorism. Since there are not enough incidents in each month of a district, we aggregate the data at yearly level for each district.

The data for crime against women is collected by the National Crime Records Bureau (NCRB), Ministry of Home Affairs. ${ }^{27}$ This dataset reports the number of cases recorded for various crimes against woman in each year of a district. However, we do not have information on whether the crime took place in rural or urban centers of a district.

Lights Data.- We use Defense Meteorological Satellite Program (DMSP)'s night time lights data which is available from the National Oceanic and Atmospheric Administration (NOAA). The data primarily captures night time luminosity of earth as observed from space and is increasingly used as a proxy for general economic development of an area (Henderson, Storeygard, and Weil, 2012). It is available on a yearly basis from 1992-2010 in small pixels across the globe. We overlay this luminosity data on Indian map so that we get a number of luminosity figures for different areas across a district in each year. Finally, we calculate the average luminosity from these numerous pixels for the district in each year. We use such average luminosity in any year and the year before for each district as our luminosity measures in the empirical analysis.

\section{Empirical Strategy}

One of the key challenges in estimating the effect of high temperatures on health is that the spatial distribution of temperature is often correlated with several unobserved factors including quality of available health care. Moreover, temperature varies across seasons and the season of birth is often correlated with several parental unobservables. Thus causal estimation of the temperature-infant mortality relationship must account for various seasonal and spatial unobservables.

In this paper, we use a fixed effect strategy to identify the effect of in utero exposure to high temperature on infant mortality. Our basic regression specification is given by the following equation:

$$
O_{i d y q}=\alpha+\beta(C D D>90 F \text { in utero and birth month })+\delta_{d q}+\theta_{q y}+\gamma_{m}+\epsilon_{i d y q}
$$

where, $O_{i d y q}$ indicates an outcome of the child $i$ born in district $d$, quarter $q$, and year $y$. When the outcome is infant mortality, it is a dummy variable which takes the value 1,000 if the child died as an infant,

\footnotetext{
${ }^{25}$ We use the data complied by Thiemo Fetzer which is available at http://southasiaterrorism.trfetzer.com/ countries / IND . html. For more details, please refer to Fetzer (2014)

${ }^{26}$ A huge share of incidents are also from Jammu and Kashmir. As of now, we do not have good data on conflict in Jammu and Kashmir.

${ }^{27}$ Data can be accessed from https://data.gov.in/catalog/crime-against-women
} 
and 0 otherwise. $C D D>90 F$ in utero and birth month refers to the total number of Cumulative Degree Days with temperature exceeding 90 Degrees Fahrenheit in utero and in the month of birth of the child. ${ }^{28}$ Since we do not have the exact date of the mother's last menstrual period to infer the date of "conception" (Deschênes et al., 2009), we consider 9 months before the birth of a child as the in utero period. We also control for rainfall during pregnancy and an indicator for DLHS survey rounds in the above specification. In some specifications, we include covariates such as maternal age, parental years of schooling, gender of the child, indicator for multiple birth, religion of the household head and night time lights of the district-year of birth and of the year prior to birth. ${ }^{29} \epsilon_{i d y q}$ is the error term.

We also control for the district by quarter of birth dummies, denoted by $\delta_{d q}$, quarter of birth by year of birth dummies, denoted by $\theta_{q y}$, and month of birth dummies, denoted by $\gamma_{m}$. The district by quarter dummies control for all differences in seasonal infant mortality at the district level by adjusting for permanent seasonal determinants of infant mortality at the district level. For example, consider the district Delhi. If it happens that unhealthy mothers give birth during the summer quarter in Delhi and the children of unhealthy mothers are more likely to die as an infant, then our estimates would be biased upwards if the district-quarter of birth fixed effects are not controlled for. In particular, the district-quarter of birth fixed effects control for all seasonal unobservables which are correlated with temperature and also affect infant mortality for Delhi. ${ }^{30}$ Similarly, the quarter of birth by year of birth dummies control for seasonal changes in infant mortality common across India and are also correlated with temperature. For example, suppose that the summer quarter in a year is particularly hot in entire India and is also hit by a swine flu epidemic across the country. Both the events will affect pregnant mothers and will increase the chances of newborns dying as an infant. Not controlling for quarter-year dummies would attribute the effect of swine flu epidemic on high temperatures, in addition to the pure heat effects. In the regression, we also control for rainfall, since rainfall is often correlated with temperature and it can independently effect pregnant mothers either through its effects on disease environment or indirectly through agricultural wages and production. The reason for controlling night time lights is to proxy for the degree of economic activity and income and infrastructure like electrification in the district around the time of birth (Henderson et al., 2012; Chand, Badarinath, Elvidge, and Tuttle, 2009). The identifying assumption is that comparing individuals born in a district-season over different years would render the event of extreme heat one faces in utero, exogenous. Thus $\beta$ measures the effect of having one extra Cumulative Degree Day above 90F during pregnancy on the chances of a child dying as an infant.

Several studies in economics use a semi-parametric specification in regressions to estimate the effects of high temperatures (Deschênes et al., 2009; Barreca et al., 2016). This involves constructing several

\footnotetext{
${ }^{28}$ Cumulative Degree Days (CDD) $>90$ F is illustrated by the following example: if, say, in district Delhi in July 2005, there are two days when temperature exceeded $90 \mathrm{~F}$. On one day, it was $95 \mathrm{~F}$ and on the other, it was $100 \mathrm{~F}$, then Cumulative Degree Days $>90 \mathrm{~F}=(100-90)+(95-90)=15$.

${ }^{29} \mathrm{An}$ anonymous reviewer has pointed out that controlling for luminosity is not common in the literature. While we control for luminosity in our regressions to account for trends in general economic improvements, we certainly agree that the economic development, in general, can be a function of weather. Based on the reviewer's suggestion, we test if luminosity is affected by temperature in India and find no evidence for the same. The results are available upon request.

${ }^{30}$ Some other permanent unobserved district-by-quarter determinants of infant mortality could be fixed differences in hospital quality or seasonal employment (Barreca et al., 2016).
} 
temperature bins, and using the number of days in each of these degree bins as explanatory variables. The advantage of this method is that it lets the effect of temperature to vary non-linearly. Since such a method involves estimating several coefficients, this is likely to provide imprecise estimates in the absence of large data. Given the size of our data, we address this problem by estimating a single coefficient for temperature during pregnancy. We choose $90 \mathrm{~F}$ as a threshold because the literature finds temperatures above $90 \mathrm{~F}$ significantly increase mortality. For instance, Burgess et al. (2013) use 10 bins of $2 \mathrm{~F}$ and find that the effect of temperature on mortality to be significant for all temperature bins above $88 \mathrm{~F}$ in India. Barreca et al. (2016) use 10 bins of $10 \mathrm{~F}$ and find the effect of high temperatures on mortality to be significant mostly for temperatures above 90F. Similarly, Deschenes and Moretti (2009) use bins of intervals of 5F and show high temperatures above $85 \mathrm{~F}$ during pregnancy reduces birth weight. In light of these studies, we show robustness of our results to other values of temperature cutoffs apart from $90 \mathrm{~F}$.

The main reason we choose infant mortality instead of neonatal mortality is to avoid the problem of harvesting. A significant part of infant mortality happens as neonatal mortality. However, exposure to high temperatures may only increase the mortality of sick newborns who would have otherwise died soon after one month of birth. We avoid this problem by considering infant mortality and hence giving a long enough time since birth. Another reason for not focusing solely on neonatal mortality is because post-neonatal mortality (which is captured under infant mortality) can also be an important driver of infant mortality with a steep socio-economic gradient. Chen et al. (2016) find that the observed higher US infant mortality relative to Europe is due entirely to higher post-neonatal mortality which is again high among disadvantaged groups. The implication is that a sole focus on examining health at birth will be incomplete, and that extending the window beyond a month to include the post-neonatal period may be a productive avenue for analyzing child morbidity.

We only look at the effect of heat and not of cold days for three reasons. First, the temperature distribution from 1948-2014 in India shows that for an average month number of days, temperature exceeded 80F is 8.08 and the number of days temperature is less than $30 \mathrm{~F}$ was 0.24 . Thus heat is far more common in India than extreme cold days. Second, agricultural production is far more likely to be affected by heat than by cold days in a sub-tropical country like India. Thus one of the main channels through which temperature may effect fetal health is not so relevant for cold days. Third, the physiological impact and the channels through which cold days affect fetal health are different from those of heat. So the measures to prevent damage to fetal health from cold days are also different from those of heat. For instance, an ASHA worker advises mothers not to take stored cooked food. Food is more likely to get spoiled in heat than in cold temperatures.

\section{Results}

\subsection{Effect on Infant Mortality}

Table 2 shows the impact of high temperatures in utero on infant mortality. Panel $A$ shows the results for households interviewed in the rural areas and Panel $B$ shows the same for the urban areas. Our preferred 
specification is when district-quarter of birth fixed effects are controlled for and hence individuals born in the same district-quarter across different years are compared. ${ }^{31}$ In column 1a, we do not include night-time lights or individual-, household-level controls. Consistent with the literature, the results show that higher temperatures in utero increase the chances of a child dying as an infant (significant at 10 percent). To interpret the numbers, consider the following example-if there are 20 days during the entire pregnancy period when the average temperature was $95 \mathrm{~F}$ and for the rest of the days the average temperature was less than 90F, then Cumulative Degree Days (CDD) exceeding 90F would be 100. This implies additional 2 deaths per 1000 infants due to extreme heat. On an average, as is reported in Table 1, CDD exceeding 90F is 85.86 for a pregnancy. So on an average, 1.83 infants per 1000 births die because of exposure to high temperatures during pregnancy. Barreca (2012) also finds similar estimates for overall mortality in the US. In column $1 \mathrm{~b}$, we include night-time lights and individual-household level controls-the impact increases marginally, and is significant at 5 percent. In column 1c, we include district-month fixed effects, instead of district-quarter fixed effects. The result actually becomes stronger under this specification and is significant at 5 percent. ${ }^{32}$

We also check a specification with district by quarter by year fixed effects in the second column of Table A1-the magnitude and sign remain similar. However, one of the challenges with this approach is to have enough sample of births within each district-quarter-year. Since we use the pregnancy history from a household survey to construct birth and death records, we do not always have enough number of births within each district-quarter-year. The problem is exacerbated by the low incidence of infant mortality in general. Naturally, the standard errors are large, although the coefficient continues to be significant at 10 percent level.

Panel B of Table 2 presents the results for households interviewed in the urban areas. The impact of high temperatures is close to zero. A number of reasons could be attributed to this finding. First, urban areas have greater access to technologies to combat heat including electrification, electric fans, air-conditioning, and so on. Also, urban areas have a more dense network of health facilities which can help treat ailing infants or pregnant mothers due to high temperatures. Second, incomes in urban India are less prone to weather shocks-more than 90 percent of employment takes place in non-agriculture sectors like manufacturing, construction etc (Chen and Raveendran, 2012). On the other hand, most income in rural areas are derived from agriculture which is again more susceptible to temperature shocks (Burgess et al., 2013).

Heterogeneous Impacts.- In Table A2, we perform a heterogeneity analysis of our main results for the rural sample. First, we check if the effects of high temperatures are different across different birth orders. We find the effects are higher for higher birth orders, compared to the first birth (the effects are not statistically significant at conventional levels). Since we have considered births only from five to seven years from the date of interview, many of these children are not adequately spaced. It is well known that pregnancies which start less than 18 months after birth are associated with greater health risk and adverse birth outcomes, including preterm birth, neonatal morbidity, and low birth weight (DeFranco, Seske, Greenberg, and Muglia, 2015).

\footnotetext{
${ }^{31}$ This specification is associated with the least standard errors among the comparable specifications.

${ }^{32}$ Our results do not change if we include postnatal temperature in our regression equation.
} 
Second, we check if the effects vary with socio-economic status of parents as measured by education of mothers. Chen et al. (2016) report that lower socio-economic status groups experience much higher post-neonatal mortality rates, and hence higher infant mortality in the US. In our context, more educated mothers perhaps are in a better position to make mitigating investments in response to temperature shocks because of greater awareness. Also, they are more likely to have less number of babies and are more likely to maintain adequate gap between successive births. Our results confirm the hypothesis-the effects of temperature are the highest for the uneducated mothers and decrease as mother education-levels go up. Third, we check if extreme heat is associated with greater infant mortality in adverse disease environment as measured by the greater incidence of Malaria. Malaria is considered to be one of the leading causes of deaths due to weather events in India. A survey of twenty-eight African countries finds the weather associated with the flourishing of malaria (sufficient rainfall, not very cold temperatures, and generally warm temperatures during pregnancy) is associated with higher infant mortality-higher predicted malaria exposure during pregnancy raises infant mortality risk by about three per thousand (Dell et al., 2014). One mechanism through which malaria is caused by high temperature is through the retreat of river margins - this may result into numerous water pools suitable for vector breeding that can cause high incidence of malaria (Shah and Steinberg, 2017). Since malaria prevalence varies by region, we take Orissa, Chhattisgarh, West Bengal, Jharkhand, and Karnataka to be the high malaria states, following Shah and Steinberg (2017). We interact high temperature exposure during pregnancy with an indicator of high-malaria states and find that there is no additional statistically significant effect of high temperature in malaria-prone states. We conclude that it is unlikely that greater incidence of malaria is driving our main results. Finally, we check if the effects vary with mother age as mother age may reflect greater ability and experience to rear a child. We find no such evidence-higher temperatures do not affect infant mortality significantly less for older mothers.

Are the effects of temperature different in the areas with historically high temperatures as compared to the areas with comparably lower temperatures but with occasional high temperature shocks? We expect the impact to be greater for the second group of areas as they are less prepared to cope with these shocks i.e have invested less in adaptation methods like housing or air cooling. In Table A3, we take the top and bottom one third districts in terms of high historical mean temperatures and run separate regressions for each set of districts. Along with the results of these new regressions, we continue to report our main result from Table 2. We find that the magnitude for the coldest districts can be close to three times large as compared to the hottest ones. Although the coefficients have large standard errors due to insufficient sample size, we can conclude that the districts with lower mean temperatures suffer the most when hit by a sudden heat wave. Overall this result tentatively supports our hypothesis.

\subsection{Robustness Check}

\subsubsection{Temperature Cut-Offs}

How sensitive are our results to the temperature cut-off of 90F? We first justify the cut-off of $90 \mathrm{~F}$ by presenting the results for local regressions of infant mortality on CDD exceeding 90F in utero and birth month in Figure 1 and Figure 2. Following Blakeslee and Fishman (2018), we regress both infant mortality 
and the temperature variables on all other explanatory variables in Equation 1. The residual terms from the infant mortality regression are then locally regressed on the z-score of residuals from the temperature regression using a locally weighted polynomial regression. We find that infant mortality follows an almost linear positive pattern with CDD exceeding 90F in utero and birth month in rural India (Figure 1) while the relationship is almost flat in urban India (Figure 2). Both these results confirm our findings in the previous section.

Our second check is based on the following observation: if there is no actual impact of temperature, and the results obtained are a matter of statistical chance, then we should expect no impact for various other temperature cut-offs. Conversely, if temperature really affects infant mortality, then the effects should be gradually increasing as we move from lower to higher cut-offs. The results in Table 3 are highly consistent with the second pattern. The impacts of high temperature are larger when the temperature cut-offs are higher-the effect is greater than thrice for $95 \mathrm{~F}$ cut-off and 1.5 times for $92 \mathrm{~F}$ cut-off as compared to our usual cut-off of $90 \mathrm{~F}$. The effects are less than half and insignificant for cut-offs $87 \mathrm{~F}$ and $85 \mathrm{~F}$. The results suggest that the prenatal exposure of temperature less than $90 \mathrm{~F}$ has minimal impact on infant mortality. This exercise reaffirms that infant mortality is actually associated with high temperatures in our data, and not an outcome of statistical chance. This is also an important result because it implies non-linearity in the effects of temperature - higher the temperature, greater is the marginal impact on infant mortality. 33 Reassuringly, high temperatures continue to have nil impact on infant mortality in urban India for all temperature cut-offs.

\subsubsection{Sample Selection}

A number of sample selection issues may cause our estimates to be biased and make it difficult to interpret the results. We consider a number of these cases below and check whether these factors are present or if they pose any serious threats to identification or interpretation of the results. One concern is that high temperatures during conception can effect fecundity in rural India, particularly for parents who are less insulated from the vagaries of weather. If household unobservables also drive the investments to temperature adaptation and health expenses, then our estimates will be biased upwards. To account for such possibility, we limit our sample to those households or mothers where births have taken place more than once during our sample period and run regressions separately with household fixed effects and mother fixed effects. Such a specification will correct for all the time-invariant household or mother level factors which can simultaneously influence adaptation to heat and health investments. The results in the first and second columns of Table 4 refer to the household and mother fixed effects specifications respectively. Both the columns suggest a positive impact like our preferred specification in Table 2 , with slightly greater magnitude for mother fixed effects. Thus we can safely rule out that our main results are driven by household or parental level unobservables.

We also check if there is evidence of selective fertility in terms of maternal observables in rural India. In Table A4, we check if higher temperature is significantly associated with maternal years of education

\footnotetext{
${ }^{33}$ Our measure of $\mathrm{CDD}>90 \mathrm{~F}$ captures the non-linearity by putting a higher weight on a day with, say, 100F than that of a day with, say, $98 \mathrm{~F}$.
} 
and age in years. We estimate two separate regressions in each case: one with district-quarter of birth fixed effects and another with district-month of birth fixed effects. We generally find no strong association of education or age of mothers with high temperatures during pregnancy. Another related concern could be that high temperature during conception or during pregnancy affects fecundity and also can increase the chance of miscarriages. Consequently, we would observe less number of births after an episode of high temperatures. In our analysis, this should not be a problem for two reasons. First, we should expect children with only superior birth endowments to survive an early life heat wave. So any measured impact of high temperature on infant mortality for such a sample is biased downwards only. Second, we regress the number of births in a district for a particular month in a particular year on temperatures till 11 months prior to that month, i.e during conception and during pregnancy of all the births in that month. In Table A5, we find no evidence of association between high temperatures and number of births under any specification. This suggests that perhaps higher temperature does not effect fecundity or cause substantial miscarriages in rural India. If, however, high temperatures increase the number of miscarriages or still births as well as the number of premature births, these two effects could cancel out resulting in no effect on the number of live births. Given our data limitations, we can not rule out this possibility. Third, another fertility response could be whether a family decides to adjust subsequent fertility if a pregnant mother in the family faced higher temperature shocks during pregnancy (possibly to take care of the sicker child). ${ }^{34}$ The results in Table A6 show that the odds of subsequent birth increases only marginally. ${ }^{35}$ However, these results should be interpreted with some caution as these fertility decisions are made till the time of survey and all mothers have not completed their entire fertility period.

Another concern with our estimates is whether differential secular time trend across districts explains the results. If extreme temperature and infant mortality have unobserved time trends, then our estimates will really be capturing these time trends instead of those of temperature. We test this possibility in Table A7 where we run the main regression, while also controlling for high temperatures from $13^{\text {th }}$ to $24^{\text {th }}$ month after birth. Since we define infant mortality as deaths within a year of birth, high temperature after first year of birth should not affect infant mortality unless our results are driven by a secular trend. We find that temperatures after first year of birth has no effect on infant mortality. Moreover, the coefficients of temperatures during pregnancy is unchanged from Table 2. We conclude that our results are unlikely to be driven by unobserved trends.

We finally check if our results are driven by migration. Since the DLHS does not have the district of birth, it is plausible that people who were relatively worse off and could not migrate might be those for whom temperature had the highest infant mortality effects (since they may have lower access to adaptive resources e.g. higher income people migrated after the temperature shock). ${ }^{36}$ However, in our context we believe that migration is not a major concern for the following reasons. Using data from the second wave of

\footnotetext{
${ }^{34} \mathrm{We}$ thank an anonymous referee for pointing this out.

${ }^{35}$ Although the coefficients are significant at 5 percent level, the magnitudes are extremely small. The results show that 6 more children are born in subsequent years per 100,000 births if the mothers are exposed to high temperatures when pregnant with their first child in the sample. Moreover, the effects are only 0.02 percent of the mean levels. So we can safely interpret these results as a nil impact of temperature on subsequent births.

${ }^{36} \mathrm{Also}$, if people with the greatest to gain from NREGA and ASHA migrated into districts that had those programs, the estimate of how much these programs mitigate the relationship between temperature and infant mortality may be overstated.
} 
Demographic Health Survey in India, Bhalotra (2008) estimates that of the children born between 1970 and 1997, 87 percent were born in the same place where the mother was interviewed. This is more restrictive than required, as the remaining 13 percent includes children born in the same district (but in a different village) where the mother was interviewed. In addition, we also use data from the $64^{\text {th }}$ round of National Sample Survey (NSS) conducted between July 2007 and June 2008 to get estimates of migration among females. Only 6.74 percent of households report at least one female member between the reproductive age of $15-49$ years have migrated for a purpose other than marriage. The number drops to 4.78 percent if we limit migration outside of the district, and to 2.17 percent if we limit outside of the state. Since the temperature variable and implementation of NREGA vary at the district level and ASHA at the state level, we believe such low migration rate is unlikely to bias our results.

\subsection{Mechanisms}

In this section, we explore the impacts of high temperature exposure on some other outcomes such as agricultural yields and income, disease prevalence, and crime and conflict. We then discuss these results in the context of potential mechanisms of impact of high temperatures on infant mortality.

Agricultural Yields.- A growing literature suggests that Indian agriculture will be strongly impacted by rising temperatures (Guiteras, 2009). If there is inadequate opportunity for consumption smoothing, fetal and maternal health can then be seriously impacted for want of income and food. Accordingly, we use the following equation to estimate the effect of heat on agricultural productivity:

$$
Y_{d y}=\alpha+\beta(C D D>90 F)_{d y}+\gamma(\text { Mean Rainfall })_{d y}+\delta_{d}+\pi_{y}+\epsilon_{d y}
$$

In the above equation, $Y_{d y}$ is the logarithm of yield of a particular crop during Kharif season in district $d$ in the year $y . \delta_{d}$ are district fixed effects and $\pi_{y}$ are the year fixed effects. Mean Rainfall measures the mean rainfall in the district during the crop growing season (from May to October) of the year. The main variable of interest is $C D D>90 F$ which measures the number of Cumulative Degree Days when temperature exceeded $90 \mathrm{~F}$ during the growing season in district $d$ and year $y . \beta$ measures the effect of one extra Cumulative Degree Day greater than $90 \mathrm{~F}$ in the growing season on the logarithm of yield.

The district fixed effects control for all permanent differences in crop yields at the district level. For instance, districts with moderate temperatures may have better land quality. If we do not control for districtfixed effects, the effects of temperature will be biased. The year fixed effects control for all year-specific changes in crop yields (like a centrally funded agricultural subsidy in a particular year) that is common across India. We also control for mean rainfall during the cropping season for every district and year. We do not need to control for season explicitly as we are only concerned about a specific crop season. Arguably, after controlling for relevant controls, year to year temperature variation within a district is exogenous, and hence $\beta$ gives an unbiased estimate of high temperatures on yield.

In Table 5, we provide the regression estimates of equation (2). The different columns refer to different crops. The results indicate that temperatures above $90 \mathrm{~F}$ during the crop growing season significantly reduce agricultural yields for all major crops. Average monthly CDD > 90F from 1948-2014 is 15 for summer 
months (May to October) in India. So if there are three months during the cropping season with average temperature, then yield for rice will decrease by 1.4 percent, bajra by 5.4 percent, cotton by 5.9 percent, soybean by 4 percent, groundnut by 1.8 percent, and jowar by 4.5 percent. The results here indicate high temperatures strongly reduce agricultural yields which in turn, can affect fetal nutrition in the absence of perfect consumption smoothing. There is ample evidence in the literature documenting imperfect consumption smoothing in rural India (Rose, 1999; Rosenzweig and Wolpin, 1993). In this context, an employment guarantee program like NREGA can help to shield against the heat-induced income shocks and enable consumption smoothing among rural households.

Agricultural Wages.- We now check if agricultural wages are impacted by the presence of abnormally hot days. An earlier study by Fetzer (2014) reports that 1 percentage decrease in monsoon rainfall is associated with 0.06 percentage points fall in agricultural wages in India. Accordingly, we use district-level nominal wage data, collected by ICRISAT from 1966 to 2010. However, we do not have data on districtlevel yearly price index, needed for converting the nominal wages into real wages. Thus we construct a measure of price index using the district-level price and production data of several crops from ICRISAT. The price index is defined by,

$$
\text { Price Index } x_{d y}=\frac{\sum_{c=1}^{n} P_{c d y} * \overline{Q_{c d}}}{\sum_{c=1}^{n} \overline{P_{c d}} * \overline{Q_{c d}}} X 100
$$

where $P_{c d y}$ is the price of crop $c$ in district $d$ for year $y, \overline{Q_{c d}}$ is the average total production for crop $c$ in district $d$ averaged across all years, and $\bar{P}_{c d}$ is the average price for crop $c$ in district $d$ averaged across all years. The downside of using this measure is that we cannot include the effect on non-agricultural commodities. However, since food purchases constitute a high proportion of the budget share in rural areas, we believe that this price index adequately captures the effect on real wages (Basole and Basu, 2015; Burgess et al., 2013)

In Table A8, we show the effect of temperature on real wages. We regress logarithm of real wage on temperature variables after controlling for yearly total rainfall, district FE, and year FE. We find that high temperature during the summer has a negative effect on male real wages, but has no effect on female real wages.

Physiological Impacts.- In Table 6, we regress incidence of diarrhea, fever or cough for children anytime within fifteen days of interview on temperatures from three periods-in utero and birth month, in the month of interview, and the preceding month of interview. ${ }^{37}$ The disease information is available in the third wave of DLHS only, so our sample size goes down a bit. ${ }^{38}$ We also report the joint significance of pre-birth temperature and the temperature around the time of interview. Table 6 indicates that children are significantly more likely to suffer from diarrhea, fever, or cough for greater temperature around the time of interview. While the pre-birth temperature is not individually significant, it is jointly significant with the temperature around the time of interview. Although the last evidence may seem to indicate that contemporaneous temperature, and not pre-birth temperature raises the risk of disease, we believe it is not an accurate

\footnotetext{
${ }^{37}$ Different villages in a district were interviewed in different months.

${ }^{38}$ The sample with disease information includes the last two children born after 2004 and were alive at the time of interview from both the rural and the urban areas.
} 
conclusion. The reason being this sample includes only those children who could possibly survive the high temperatures during birth, implying they are a positively selected sample with better birth outcomes. In other words, the estimate for pre-birth temperature on incidence of disease is downward biased and underestimates the true impact. Moreover, the information on disease is only for two weeks prior to the interviewall interviews happening around autumn and winter time would fail to report many diarrhea cases, while it would be greater for interviews around summer and rainy season. A better measure which would be free from this seasonal pattern, is the number of incidences of disease in past one year. Unfortunately, we don't have this information in our data. We conclude this subsection by noting that our result suggests two indirect mechanisms through which high temperatures can effect fetal health. First, increased temperature can lead to greater incidence of diseases in general, so that pregnant mothers can also suffer from them. This can cause loss of nutrition to the fetus. Second, siblings and other children in the households can fall sick due to high temperatures while the concerned child is in utero. For resource-constrained households, this implies diversion of resources from pregnant mothers to the treatment of these sick children. Naturally, fetal health is adversely impacted. This explanation, in part may account for somewhat greater in utero impact of temperature on children of higher birth order.

In summary, we find suggestive evidence that increased disease prevalence caused by high temperatures can be put forward as a major reason for child mortality. While contemporaneous temperature is strongly responsible for higher incidence of disease, there is indirect evidence that pre-birth temperature is also responsible for the same.

Crime and Conflict.- We now test if high temperatures lead to either increased conflict or more crime against women, which in turn, may affect infant mortality. We particularly test for crime against women as crime against women is frequently found to be a mechanism for consumption smoothing in times of agricultural distress (Miguel, 2005; Sekhri and Storeygard, 2014). Crimes with extreme outcomes like dowry deaths and "witch" killings or relatively less severe crimes like cruelty by husband's family or assault are used for the purpose. ${ }^{39}$

Thus we use the following empirical specification:

$$
Y_{d y}=\alpha+\beta(C D D>90 F)_{d y}+\gamma(\text { Mean Rainfall })_{d y}+\chi_{d y}^{\prime} \gamma+\delta_{d}+\pi_{y}+\epsilon_{d y}
$$

In this equation, $Y_{d y}$ represents the number of incidents of crime in district $d$ in year $y$ and $\delta_{d}$ are the district fixed effects and $\pi_{y}$ are the year fixed effects. $(C D D>90 F)_{d y}$ captures the number of CDD exceeding $90 \mathrm{~F}$ in district $d$ and year $y$. Since the data on crime is at year level, the issue of seasonality does not apply. $\chi_{d y}^{\prime}$ includes night time lights for the district in the current and preceding years of the event. The regressions are weighted by the district population as of Census 2001.

Table A9 shows the impact on a host of crime against women. Our dependent variables refer to the number of crimes in a year at district level such as rape, kidnapping and abduction, and dowry deaths along

\footnotetext{
${ }^{39}$ These crimes may force women to move out of the household and migrate to their maternal households. We also study the effect of temperature on other types of crime in India. For our purposes, we use district level crime data from the National Crime Records Bureau (NCRB) for the years 2001-2010. We actually find an increase in crime like dacoity, but there is no consistent pattern as we see no effects on a range of other serious crimes like murder and kidnapping. The results are available upon request.
} 
with less heinous crimes like insult. We find that the impact of increased temperature in a year on the number of crimes against women is close to zero and is insignificant.

In Table A10, we show the effect of temperature on reported incidents of conflict. Based on some key words, we have classified newspaper incidents as "Maoist" (for incidents related to armed left wing insurgency), Islamic terrorism, armed separatist movements (primarily in the North Eastern states of India), and others. We also run a separate regression for the total number of incidents related to Maoist, Islamic Terrorism, and separatist movements to improve statistical power. However, we find no significant impact for any type of conflicts. ${ }^{40}$ However, one limitation of our analysis in this section is that such data suffer from the problems of under-reporting. If increased temperature actually leads to increased incidents but are not reported at the same rate, especially for the remote areas, then we will not be able to detect any impact in our analysis.

We conclude this section by noting that our results on the effects of extreme heat on increased deaths of infants seem to be driven by reduced income and increased disease prevalence of diarrhea and fever. Increased crime and conflict is unlikely to be a mechanism in our context.

\section{Impact of Policies in Modifying High Temperature-Mortality As- sociation}

\subsection{Mitigation}

In this section, we analyze the possible modifying impact of one nationwide rural public workfare program (NREGA) and one rural basic health intervention program (ASHA) together, as both the programs were introduced around the same time. We use the phased introduction of NREGA to identify its impact on the effects of high temperatures in utero on infant mortality. Since NREGA was initially introduced in some districts in 2006, no districts in our sample were exposed to NREGA prior to that year. Thus it creates four groups of mothers within a district-quarter: a) mothers exposed to high temperatures during pregnancy but did not have NREGA, b) mothers neither exposed to high temperatures during pregnancy nor had NREGA, c) mothers exposed to high temperatures during pregnancy and had NREGA, and d) mothers not exposed to high temperatures during pregnancy but had NREGA. We use comparison across these groups to identify the effects of NREGA in reducing the effects of high temperatures during pregnancy on infant mortality while controlling for the effects of ASHA.

Similarly, ASHA was introduced heavily in 18 high focus states from 2005 onward. Since our sample includes newborns from 1998 till 2007, we again have four groups of children depending on the exposure to high temperatures and the receipt of ASHA during pregnancy. We use comparison across these groups to identify the effects of ASHA while controlling for the impacts of NREGA.

We now estimate the following equation for the rural sample:

\footnotetext{
${ }^{40}$ It is important to distinguish between conflicts like civil wars which can result from conflict over resources from general separatist movements and Islamic terrorism which may be driven by factors like political rights and ideology. Ideally, the effect of temperature (if any) should be observed for the first type of conflicts only.
} 
This equation is defined similar to equation (1), except now we have added the exposure variables, $A$ and $N$, and their interactions with temperature. These exposure variables measure the number of months from the time ASHA or NREGA started in a district till the child is born. ${ }^{41}$ Apart from interacting the program exposures with temperature, the estimating equation also controls for the main effects of ASHA and NREGA. $\chi_{i d y q}$ includes controls like total rainfall in the district of interview from 9 months prior to birth and the month of birth, DLHS survey round fixed effects, and a number of state-level yearly controls-number of females per 1,000 males, percentage of women literate, percentage of population living in urban area, logarithm of of per capita real net state domestic product (in 2004-05 Rupees), public health expenditure as percentage of state GDP, own tax revenue as percentage of state GDP, logarithm of aggregate government expenses excluding public health expenses, logarithm of social expenditure excluding public health expenses, and per capita real public health expenses (in 2004-05 Rupees). We obtain these state level yearly controls from a dataset provided in Barenberg, Basu, and Soylu (2017). ${ }^{42}$ The regressions also control for district-quarter of birth (or sometimes district-month) fixed effects, quarter-year of birth fixed effects, birth month (except when we control for district-quarter fixed effects) fixed effects, and sometimes includes covariates such as maternal age, parental years of schooling, gender of the child, indicator for multiple birth, religion of the household head, and night time lights of the district-year of birth and of the year prior to birth. Our coefficients of interest are $\lambda_{a}$ and $\lambda_{n}$.

Table 7 presents the results from fitting the equation above. Since we use a continuous variant of each program exposure which indicates the number of months a child is exposed to a program in utero, we set any postnatal exposure equal to 0 . The table also reports on tests of whether prenatal exposure to ASHA or NREGA modifies the temperature-infant mortality relationship. We consider specifications in which the mitigating effect of each program enters individually, as well as the ones in which both programs enter the same specification. However, all these regressions control for the main effects of both NREGA and ASHA together.

In the first column, we include mitigation due to ASHA only and find that it is associated with a sizable and statistically significant decrease in infant mortality due to hot days in utero in the 1998-2007 period. The estimate suggests, for instance, if a child is born one month after ASHA started, exposure to ASHA in

\footnotetext{
${ }^{41}$ An alternative exposure measure could be the months of in utero (plus birth month) exposure to each program. Thus, the maximum exposure to any program is 10 months for this new measure. Such an exposure measure will not distinguish between two children who are born, say, 10 months after the program started and 24 months after the program started. The measure used in equation (3) has the advantage that it can capture the lagged effect of each program more effectively. However, our results are very similar for both exposure measures-please refer to Table A11 for the regression results of this alternative measure. We take July 2005 as the start month of ASHA for both versions of months of exposure to ASHA.

${ }^{42}$ The data on some of the state-level controls are missing for some states (particularly Delhi and Manipur) for some years. Thus we lose these observations when we include all the state-level controls in a regression. However, the data on the number of females per 1,000 males, percentage of women literate, and percentage of population living in urban area are consistently available for all states and all years. If we run the regressions while restricting the set of state-level controls to these three variables only, we do not miss any state-year observation. However, our results remain similar.
} 
utero is associated with a decrease in the mortality effect of $C D D>90 F$ days by 0.2 percentage points; this is roughly 10 percent of the effect of $C D D>90 F$ days in our sample period. Barreca et al. (2016) also report a 10 percent modifying impact of air conditioning on mortality due to hot days. Column 2 reports estimates when we include the mitigation due to NREGA only and find similar impact.

As the results show, it appears that both the programs are effective in moderating the effects of heat individually. It is, however, possible for some overlap between NREGA and ASHA. In our data, a greater proportion of districts in high focus states had access to NREGA in phase 1, even though phase 1 implementation of NREGA involved both high and low focus states. This is because while ASHA was primarily implemented in poorer states, NREGA was also initially introduced in the most backward districts. This creates a possibility that access to ASHA is correlated with access to NREGA. We formally show this in a non-parametric plot in Figure A3 where we plot the residual z-score of NREGA exposure against the residual z-score of ASHA exposure. To produce these plots, the two exposure variables are both separately regressed on our usual individual-household-level covariates, night time lights, and state-yearly level covariates, birth year, and districts. The residual terms from the NREGA regression are then locally regressed on the z-score of residual terms from the ASHA regression. The plot clearly reveals a positive relationship between the two exposure variables.

Accordingly, we include mitigation terms for both ASHA and NREGA in the remaining columns. We find that the relevant coefficient for mitigation due to NREGA becomes close to 0 and insignificant, while the impact of ASHA slightly goes up. The results remain unchanged when we include DMSP mean night time lights and different individual controls in column 4. Since the standard errors go up for the mitigation coefficients (due to multicollinearity), we report the joint significance levels of the mitigation coefficients and found them to be jointly significant. To account for the possibility that NREGA may improve the mitigation due to ASHA despite having no independent impact of its own, we also include an interaction of ASHA, NREGA, and heat in column 5. However, the triple interaction term is close to 0 and is statistically insignificant. We can think of two plausible reasons for NREGA having no effect, although we do not have enough conclusive evidence in support of the same. First, the theory that links NREGA to infant mortality is not clear-cut. It is possible that NREGA is associated with greater possibility of pregnant woman to exert physical labor under extreme heat (either because they themselves participate in the scheme or they have to do more household work as other household members are away for work under NREGA), thus having negative effect on the health of a child in utero. On the other hand, the extra income from participation in NREGA has a positive impact on health due to greater spending on nutrition, health care, heat-mitigating mechanisms etc. It is possible in our case that both these effects cancel each other out, leading to no positive net mitigating impact. Second, we focus on the impact of NREGA for 2006 and 2007, which correspond to just two years of program implementation. The take up rate by this time may not have been high enough to generate sufficient benefits. ${ }^{43}$

We repeat the exercise from columns 4 and 5 in 6 and 7 -instead of district-quarter and birth month fixed

\footnotetext{
${ }^{43}$ Klonner and Oldiges (2014) find that NREGA has increased consumption among scheduled caste and scheduled tribe (SC/ST) households. For our sample, however, we do not find the mitigation of NREGA to be significant among SC/ST households as well (results not shown).
} 
effects, we now include district-month fixed effects. Interestingly, the sign, magnitude, and significance levels for the mitigation coefficients are very similar with the original specification. This result further confirms that our results are not driven by district-specific seasonality in any way. ${ }^{44}$

We considered mitigation due to ASHA and NREGA from prenatal exposure only in Table 7, because we were primarily interested in moderating the effect of prenatal exposure to heat. However, postnatal exposure to these programs can also moderate the effects of prenatal exposure to heat. So, we repeat the exercise for Table 7 in Table A12 where we allow for postnatal exposure. ASHA and NREGA exposure now measure the number of months from the time ASHA or NREGA started in a district till the child becomes one year old. All the earlier conclusions continue to hold but the magnitudes of the coefficients now go down.

How can ASHA modify the heat-infant mortality relationship? Since high temperature during pregnancy is mainly responsible for deaths among infants, one natural starting point is that the ASHA workers possibly improved the antenatal services among pregnant mothers. We check for this hypothesis in our birth sample. As earlier, we control for parental background, district fixed effects, month of birth, and birth quarter-birth year fixed effects in the regressions. In Table A13, we show that ASHA workers are actually effective in increasing the use of prenatal care. A mother from a high focus state is 13 percent more likely to receive any antenatal care and 20 percent more likely to receive iron supplements while pregnant. These findings are consistent with a similar program in Indonesia where the introduction of village midwives has increased the receipt of antenatal care and iron tablets by remarkably similar magnitudes (Frankenberg, Buttenheim, Sikoki, and Suriastini, 2009).

Postnatal exposure to ASHA workers can also help moderate the effects of heat. This could happen due to increased postnatal care provided by the ASHA workers. ${ }^{45}$ Since we do not have exact information on postnatal care that ASHA workers might be providing, we begin by considering incidence of vaccinations as a proxy for postnatal care. In fact, a study finds that the introduction of ASHA is associated with significant increases in the coverage of specific vaccines, full immunization, and a reduction in the incidence of infants with no immunization in high focus states (Rao, 2014). We check if this is true in our data as well. Table A14 confirms the effectiveness of ASHA workers in providing greater vaccinations and Vitamin A supplementation. A child from a high focus state, for instance, is 8 percentage points more likely to receive a vaccination against BCG or measles. In addition, ASHA workers can also provide valuable healthcare information to mothers. These information acquired during prenatal or postnatal period can be helpful in moderating the effects of heat. In Table A15, we find evidence that the implementation of ASHA is associated with mothers being more informed about danger signs of diarrhea and pneumonia. In addition, mothers exposed to ASHA workers are more likely to report that they have acquired advice regarding these diseases from a health care worker. For the 1937 Danish home visiting program, Wüst (2012) reports a significant and positive effect on infant survival rates of around $5-8$ lives saved per 1000 live births. The

\footnotetext{
${ }^{44}$ We have done an additional check to see if the mitigation of prenatal temperature exposure follows any significant non-linear pattern for temperature above 90F. We considered first, second, and third terciles of bins of days exceeding 90F in utero and birth month instead of $C D D>90 \mathrm{~F}$. We do not find any significant non-linearities in mitigation. However, the estimates are imprecise. The results are available upon request.

${ }^{45}$ We thank an anonymous referee for pointing this out.
} 
study finds that the essential driving force was the decrease in mortality from diarrhea-related causes with the important mechanism being the nurses' promotion of proper infant nutrition. Much like ASHA, the Danish program required trained nurses to visit all infants during the first year of life about ten times. Their duties included encouraging mothers to breastfeed, keep the home environment clean, and refer ill infants to doctors for treatment (Hjort, Slvsten, and Wst, 2017). In our study, however, please note that we do not have adequate information to pinpoint the exact channels through which ASHA workers can moderate the effects of heat. The increased incidence of vaccinations and better information should be treated as a general proxy of greater access to postnatal care. We conclude by noting that these patterns are broadly consistent with the decline in heat-induced infant deaths operating through the functions of ASHA workers.

\subsection{Robustness}

One threat to the identification for the partial introduction of ASHA program is that the high focus states may have also received priority in other government programs which could actually be driving the temperatureinfant mortality relationship. For this purpose, we use the village survey from DLHS-III which has collected information on the availability of several government programs. Table A16 shows the implementation of different public programs by high and low focus states. Importantly, we find that high focus states are around 50 percent more likely to receive an ASHA worker compared to remaining India. We also find that high focus states are actually less likely to receive (with the exception of two employment programs) other government programs like Integrated Child Development Service (ICDS) or Indira Awas Yaojna (IAY). However, the differences are extremely small as compared to the respective mean implementation levels. For instance, high focus states are only 3 percent less likely to receive ICDS and 2 percent more likely to receive Jawahar Rozgar Yojana (JRY) with mean implementation levels of 84 percent and 28 percent respectively. These differences primarily stem from the variation in the efficiency of the pubic sector in implementing these programs. Moreover, many of these programs (like ICDS) actually predate ASHA. Since we will be comparing within districts over time, these differences should not bias our result. ${ }^{46}$

Another potential threat to our identification is the presence of pre-existing trends. It is possible that the effects of temperature were declining in ASHA-implementing states, prior to the introduction of ASHA (or NREGA). We test and deal with this possibility by undertaking a two-step econometric approach, followed in Greenstone and Hanna (2014). In the first step, we estimate a traditional event study model to see the mitigation impact of each policy for each year in our sample. Plotting the event study graph helps us to visually examine whether heat-induced infant mortality in adopting regions were on differential trends. We first estimate the following equation:

\footnotetext{
${ }^{46}$ The only case where the difference of magnitude is large is the Sanitation Program which the high focus states are 28 percent less likely to receive. However, even if there is a systematic preference of implementing sanitation programs in favor of low focus states, our estimates will be affected only if these programs are also effective in dealing with heat and are also implemented around same time as ASHA. In that case, our estimates will only be downward biased and will be an underestimate of the true impact.
} 
$O_{i d y q}=\alpha+\beta(C D D>90 F)+\sum_{\tau} \phi_{\tau}(C D D>90 F)_{d y} A_{\tau}+\sum_{\rho} \lambda_{\rho}(C D D>90 F)_{d y} N_{\rho}+\sum_{\tau} \pi_{1 \tau} A_{\tau}+\sum_{\rho} \pi_{2 \rho} N_{\rho}+\chi_{i}^{\prime} \psi+\delta_{d q}+\theta_{q y}+\gamma_{m}+\epsilon_{i d y q}$

In this equation, $\tau$ runs the entire sample period from 1998 to 2007. $\rho$ is the difference between the year of birth and the year NREGA was implemented in the district where the child is born. $A_{\tau}$ is an indicator that takes the value one if the child is born in year $\tau$ in an ASHA state, and zero otherwise. Similarly, $N_{\rho}$ takes the value one when the difference of years between NREGA implementation and birth is $\rho$, and zero otherwise. $\rho$ is normalized so that it is equal to zero in the year NREGA is enacted in a district. Since we have separate program exposure variables for NREGA and ASHA, so each policy's impact is conditioned on the other policy's impact. $\chi_{i}$ includes controls like temperature interacted by year dummies, total rainfall in the district of interview from 9 months prior to birth and month of birth, DLHS survey round fixed effects, and a number of state level yearly controls-number of females per 1,000 males, percentage of women literate, percentage of population living in urban area, logarithm of of per capita real net state domestic product (in 2004-05 Rupees), public health expenditure as percentage of state GDP, own tax revenue as percentage of state GDP, logarithm of aggregate government expenses excluding public health expenses, logarithm of social expenditure excluding public health expenses, and per capita real public health expenses (in 2004-05 Rupees). $\delta_{d q}$ are district-quarter fixed effects, $\theta_{q y}$ are quarter-year fixed effects and, $\gamma_{m}$ are month of birth fixed effects.

Figure A4 and Figure A5 plot the estimates of $\phi_{\tau}$ and $\lambda_{\rho}$ along with the confidence intervals from the above equation. We treat the year before the implementation of the programs as the omitted category. A visual inspection of Figure A4 shows a clear shift in the estimates from 2005, the year ASHA was implemented. Before treatment implementation, estimates for the event time indicators are usually close to zero. However, a mild shift is observed in the year 2001 so that we cannot rule out an existence of pre-trend completely from mere visual inspection. Finally, a visual inspection of Figure A5 does not reveal existence of any significant pre-trends before the year of implementation. ${ }^{47}$

However, there are two issues with the above regression-specification. First, we do not have sufficient years during post-implementation periods as far as ASHA is concerned. This is because ASHA was implemented in 2005 and our sample ends in 2007. Second, we cannot distinguish among prenatal, postnatal, and post-infancy time periods because of the yearly nature of the graphs. ${ }^{48}$ To address this issue, we estimate a slight variant of the traditional event-study model. We re-estimate equation (4) while re-defining the exposure variables in the following way: instead of year of birth, $A_{\tau}$ 's and $N_{\rho}$ 's in the equation now indicate separate indicator variables, of $3-5$ month bins indicating the age of a child (in months) when ASHA and NREGA are introduced respectively in her district of birth. Please note that we have open endpoints on both sides of the event time axis. Again, since we have separate program exposure variables for NREGA and

\footnotetext{
${ }^{47}$ Though there may be a mild downward trend between the years 9 and 6 , the trend sharply reverses. Moreover the line remains mostly flat and close to zero moving left from year 4.

${ }^{48}$ For example, a child born in January 2005 has no exposure while a child born in December 2005 can have full prenatal exposure to ASHA.
} 
ASHA, so each policy's impact is conditioned on the other policy's impact. The parameters of interest are the $\phi_{\tau}$ 's and the $\lambda_{\rho}$ 's, which measure the average mitigation of heat-induced infant mortality in the months before and after the implementation of each policy. Controls in the regression include total rainfall in the district of interview from 9 months prior to birth and the month of birth, DLHS survey round fixed effects, and the state-level yearly controls, mentioned earlier.

Figure A6 and Figure A7 plot the estimates. Figure A6 shows a program effect for both prenatal and postnatal exposure (moving from -19 months and earlier to the right till $10-12$ months after birth in the graph). The effects are negative or close to zero during this time period. We may expect that the estimated effects for consecutive time periods after treatment initiation to increase thus reflecting the program's increasing effectiveness: the graph, however, fails to reveal that-the lack of precision in estimates prevents us from drawing a definite conclusion regarding this matter. Also we observe the coefficients to be negative more than a year after a child is born (16 months and more). Those estimates are, however, noisy as the confidence intervals are larger so that we cannot completely rule out the existence of pre-trends. Figure A7 shows that NREGA has no effect in moderating the effects of heat and a visual inspection of the estimates do not reveal any evidence of pre-trends. However, please note that most of the coefficients are estimated imprecisely.

In the second step of the econometric approach, we formally test if the policies are associated with reduction in heat-induced infant mortality. More specifically, we check if there are shifts in these coefficients at the time of the introduction of each policy. The test allows us to check whether the introduction of a policy is associated with a greater decline in heat-induced mortality even in the presence of a downward pretrend. Both the figures for ASHA seem to suggest this possibility. Accordingly we estimate the following equations:

$$
\begin{gathered}
\hat{\phi}_{\tau}=\eta_{0}+\eta_{1} I(\text { policy }>0)_{\tau}+\eta_{2} \tau+\epsilon_{\tau} \\
\hat{\lambda}_{\rho}=\xi_{0}+\xi_{1} I(\text { policy }>0)_{\rho}+\xi_{2} \rho+\epsilon_{\rho}
\end{gathered}
$$

We estimate equations 5 and 6 separately for both the yearly and monthly versions of the event study model, given by equation 4 (a hat represents estimated coefficients). $I$ (policy $>0$ ) is an indicator variable for whether the policy is in force (the policies are ASHA for equation 5 and NREGA for equation 6). Each equation controls for a linear trend in these coefficients to adjust for any possible differential preexisting trends in adopting states or districts-a mean shift in the coefficients at the time of the introduction of the policy will be evidence in favor of a positive effect of the policy. Each equation is weighted by the inverse of the standard error of the estimates to account for differences in precision in the estimation of these parameters. Greenstone and Hanna (2014) note that the standard errors for the above equations are heteroskedastic-consistent. Please note that our coefficients of interest are $\eta_{1}$ and $\xi_{1}$ which test for a mean shift in heat-induced infant mortality after the relevant policy's implementation.

The results are presented in Table A17 and Table A18. Column 1 in each table uses estimates from the yearly version of equation 4 and column 2 uses estimates from the monthly version of the same equation 
as the dependent variables. In column 1 of Table A17, we find that there is a significant mean shift in coefficients at the downward direction when ASHA is introduced. ${ }^{49}$ Column 2 also shows a strong negative effect but the results are insignificant. The estimates in Table A18 show no shift in the coefficients when NREGA is introduced. The regression results thus confirm our previous finding that the introduction of ASHA is strongly associated with a fall in heat-induced infant mortality, while no such effects exist for NREGA.

To complement the above analysis, we implement a structural break test by adapting the Quandt Likelihood Ratio (QLR) statistic for a time series following Greenstone and Hanna (2014) and Piehl, Cooper, Braga, and Kennedy (2003). The idea is to check for a structural break in the policy parameters $\eta_{1}$ and $\xi_{1}$ near the true date of adoption of the respective policies. Two steps are involved in the test (Greenstone and Hanna, 2014). First, we estimate equation 5 and equation 6 for a number of dates as placebo policy implementation dates (including the actual date) repeatedly. We test for break dates by trimming between ten to twenty percent of the event time in each time-series to keep a sufficient amount of data outside the window. Then we carry out Chow-tests for parameter constancy which essentially involve calculating the $F$-statistics associated with the null hypothesis that $\eta_{1}=0$ and $\xi_{1}=0$ separately. This step helps to identify the date with the sharpest change in the parameter value (defined as the date with the sharpest change in the $F$-statistic). The second step involves the QLR test to select the maximum of the $F$-statistics to test whether the change in parameters is different than zero (i.e., whether there is a break). However, the maximum $F$-statistic does not necessarily converge to an $F$ distribution but to an asymptotic distribution (Andrews, 1993). So the maximum $F$-statistic needs to be compared with the critical values provided in Andrews (1993, 2003). If we fail to find a break or find a break much before the actual date of policy implementation, then we conclude that the policy is ineffective and this will undermine any findings in Table 7 and Table A12. In contrast, if we find a policy effect at or slightly after the actual date of policy implementation, then that would support those earlier findings of a policy effect.

Our results of the QLR test are presented in Table A19. Panel A reports the results for ASHA. For the yearly event study estimates from Figure A4, the maximum $F$ corresponds to the year 2005. In other words, the test identifies the actual implementation year of ASHA to be the event date with the most substantive break. Moreover, the null hypothesis of no break in 2005 is rejected at 10 percent level when compared to the critical values provided in Andrews (2003). ${ }^{50}$ On the contrary, we fail to reject the null of no structural break for the time series of the estimates from Figure A6-while the largest $F$-statistic occurs during 10 to 12 months after birth, it is not statistically significant at conventional levels. Please recall that the estimates in Figure A6 are noisy enough to draw any definite visual conclusion, regarding the mitigating impact of ASHA. Thus the test suggests that the case for mitigation due to ASHA for the second (3-5 month-level) event study is not as strong as the case for the same in the first (year-level) event study.

Panel B of Table A19 provides the QLR test results for NREGA. The null of no structural break cannot

\footnotetext{
${ }^{49}$ Although the trend term is significant at 10 percent level of significance, we can ignore it because of the small magnitude. Also its positive sign implies the mitigation effect on heat-induced infant mortality to be actually going up over time, rather than going down.

${ }^{50}$ For testing one parameter, the critical values at $10 \%$ level of significance for $10 \%, 15 \%$, and $20 \%$ trimming are $7.58,7.12$, and 6.73 respectively (Andrews, 2003).
} 
be rejected for the time series in Figure A5, which is consistent with the results in Table 7 and Table A12. Finally, we find a significant break (at 1\% level) for the time series in Figure A7 at 4 to 6 months after birth. Since the magnitude of the underlying values in the time series in Figure A7 is close to zero with large confidence intervals, this structural break is of limited practical importance as far as mitigation is concerned.

To sum up this subsection, we find evidence of a structural break in one version of the event study of ASHA while we fail to find the same for the second version of the event study. Thus the above analysis is not conclusive in ruling out the null of no mitigating impact of ASHA. The reason lies in the imprecision in the underlying event study estimates. For NREGA, we again find no evidence of mitigation.

\section{Discussion and Conclusion}

Average global temperatures are predicted to rise along with more frequent extreme weather events. Among other things, this global warming is expected to change disease patterns, affect agricultural production, and reduce water availability. The influence of weather, including greater temperature is especially more keenly felt by rural populations in developing nations who still rely on weather-dependent agriculture for their livelihood. Moreover, these areas also lack reliable health infrastructure to deal with heat and other weather-related illnesses. Aggressive mitigation efforts in terms of reducing greenhouse gas emissions are required to prevent further global warming. However, mitigation efforts are costly to the current population as it would involve shifting of investments from increasing current production now, to a cleaner technology for a better future. Determining the optimal amount of investment in mitigation effort thus entails correct measurement of costs from predicted global warming, including costs to human health for rural parts of the developing countries.

This paper presents new evidence about the effects of high temperature in utero on infant mortality and its possible mitigation. First, we show that high temperatures during pregnancy can lead to significant increase in deaths among infants. Using pregnancy history of mothers from a large household survey in India, we are able to show that 2 children die as infants per 1000 births due to high temperature exposure during pregnancy. The temperature effects on infant deaths are limited to rural India only and are heterogeneous across different population subgroups. The results are robust to various tests such as alternate specifications, inclusion of mother or household fixed effects, different temperature cut-offs, and several placebo tests. We identify reduced agricultural yields and wages and greater incidence of diseases like diarrhea (which are responsible for most infant deaths in developing countries), to be the proximate mechanisms of heat-induced infant mortality in our sample. We rule out mechanisms involving conflict, violence, and crime against women.

Further, we provide new evidence on the efficacy of public policy as an adaptation strategy in a lowincome setting: we show a large scale public workfare program which provides a guaranteed employment to households in rural areas (NREGA) is not effective and a community health care worker program (ASHA) is effective in reducing the ill-effects of high temperatures during pregnancy on infant mortality. Employment guarantee helps households to smooth consumption in times of weather-induced income shocks and helps 
in making heat-mitigating health and non-health investments. Exposure to a community health worker, on the other hand, ensures timely receipt of treatments for weather-induced diseases and physiological stress to pregnant mothers. The community health workers can also provide useful information on various healthissues and can raise general health awareness in a community. Using the roll-out of the programs for identification, this paper finds that ASHA mitigates the effects of heat during pregnancy on infant mortality, while NREGA has no independent impact. The heat-mitigating impact of improved health services is important in at least two ways. On the one hand, the literature does not find access to health care modifies temperature-mortality relationship significantly (Barreca et al., 2016). On the other hand, our paper is the first to examine a health intervention (as opposed to doctors per capita in Barreca et al. (2016)) as a possible heat-mitigating adaptation strategy. We show that the implementation of ASHA is associated with greater antenatal care, greater postnatal care, and a greater provision of important healthcare information to mothers. We argue that these factors have potentially played a large role in modifying the temperature-infant mortality relationship. We believe that one of the main reasons why NREGA fails to mitigate heat-induced infant mortality in our data is due to the short exposure window of less than 2 years in our sample. We follow a two-step econometric approach to deal with possible pre-trends driving the mitigation results. Though we find some evidence of a structural break in the mitigation impacts around same time as the policy of ASHA workers were implemented, they should be interpreted with caution for reasons described earlier.

Our estimates are based on short run fluctuations of weather only. If these estimates were to be useful for estimating the costs of long run climate change, we need to make assumptions about the expectations of agents and their access to adaptive investments (Lemoine, 2017). If the agents have perfect expectations about weather (possibly because of improvements in weather forecasts) and have access to adaptive investments, and if these investments have positive returns, then there will be no effects of weather shocks on infant mortality in the future. However, our estimates still remain useful for two purposes. First, it provides a lower bound of costs of continuing in the status quo. For example, if the method of forming expectations of the future weather remains unchanged (partly because of no improvements in forecasting technology, say) and if individuals make no additional adaptive investments than they are making now, then our estimates provide a lower bound of the costs of climate change. Since the society may need to make some decisions about investments in adaptive technology (for instance, on innovations of producing cheap air conditioning) at the current time, our estimates are useful in making this cost-benefit analysis. Second, to an extent the technology of adaptive investments is not entirely known, our estimates from ASHA provides information on the effectiveness of such adaptive measures.

Achieving a global agreement over an aggressive mitigation strategy is difficult. Hence some effects of global climate change are considered unavoidable. Adaptation strategies i.e actions to reduce the adverse effects of climate change are thus going to be a critical part of the global climate strategy (Barreca et al., 2016). Since the role of public policies is critical in developing nations, it is important to explore possible policy measures which can serve as adaptation strategies to deal with the impacts of global climate change on human health. Our analysis finds sizeable heat-mitigation impacts (on infant mortality) of access to health care for pregnant rural mothers through a community health care worker program. These results open up a new and important area of research regarding the evaluation of various public policies in quantifying 
their potential to limit damages from climate change in various domains like health, income, investment in clean technology, and so on. Rising global temperatures will continue to affect greater sections of the population, which would necessitate greater adoption of adaptation strategies. Gaining further knowledge and insight regarding both short term and longer term impacts of various adaptation strategies, both private and public, is thus of supreme importance. 


\section{References}

Adhvaryu, A., N. Kala, and A. Nyshadham (2014). The light and the heat: Productivity co-benefits of energy-saving technology.

Adhvaryu, A. and A. Nyshadham (2015). Return to treatment in the formal health care sector: Evidence from tanzania. American Economic Journal: Economic Policy 7(3), 29-57.

Ahsan, M. N. (2015). Do parents selectively time birth relative to ramadan? evidence from matlab, bangladesh.

Alexander, K. A., M. Carzolio, D. Goodin, and E. Vance (2013). Climate change is likely to worsen the public health threat of diarrheal disease in botswana. International journal of environmental research and public health 10(4), 1202-1230.

Almond, D. and J. Currie (2011). Killing me softly: The fetal origins hypothesis. The journal of economic perspectives: a journal of the American Economic Association 25(3), 153.

Almond, D., J. Currie, and V. Duque (2017). Childhood circumstances and adult outcomes: Act ii. Technical report, National Bureau of Economic Research.

Andalón, M., C. Rodriguez-Castelan, V. Sanfelice, J. P. Azevedo, and D. Valderrama (2014). Weather shocks and health at birth in colombia. World Bank Policy Research Working Paper (7081).

Andrews, D. W. (1993). Tests for parameter instability and structural change with unknown change point. Econometrica: Journal of the Econometric Society, 821-856.

Andrews, D. W. (2003). Tests for parameter instability and structural change with unknown change point: A corrigendum. Econometrica 71(1), 395-397.

Banegas, J., F. Rodriguez-Artalejo, A. Graciani, and J. De La Cruz (2001). Month of birth and height of spanish middle-aged men. Annals of human biology 28(1), 15-20.

Barenberg, A. J., D. Basu, and C. Soylu (2017). The effect of public health expenditure on infant mortality: Evidence from a panel of indian states, 19831984 to 20112012. The Journal of Development Studies 53(10), 1765-1784.

Barreca, A., K. Clay, O. Deschenes, M. Greenstone, and J. S. Shapiro (2016). Adapting to climate change: The remarkable decline in the us temperature-mortality relationship over the twentieth century. Journal of Political Economy 124(1), 105-159.

Barreca, A. I. (2012). Climate change, humidity, and mortality in the united states. Journal of Environmental Economics and Management 63(1), 19-34.

Basole, A. and D. Basu (2015). Non-food expenditures and consumption inequality in india. 
Basu, R., B. Malig, and B. Ostro (2010). High ambient temperature and the risk of preterm delivery. American Journal of Epidemiology 172(10), 1108-1117.

Basu, R. and J. M. Samet (2002). Relation between elevated ambient temperature and mortality: a review of the epidemiologic evidence. Epidemiologic reviews 24(2), 190-202.

Bhalotra, S. (2008). Sibling-linked data in the demographic and health surveys. Economic and Political Weekly, 39-43.

Bharadwaj, P. and L. K. Lakdawala (2013). Discrimination begins in the womb. Journal of Human Resources $48(1)$.

Bhowmick, R. (2016). Evaluating impact of community health workers on maternal and child health behavior in india.

Blakeslee, D. S. and R. Fishman (2018). Weather shocks, agriculture, and crime evidence from india. Journal of Human Resources 53(3), 750-782.

Bohlken, A. T. and E. J. Sergenti (2010). Economic growth and ethnic violence: An empirical investigation of hindumuslim riots in india. Journal of Peace research 47(5), 589-600.

Bouchama, A. and J. P. Knochel (2002). Heat stroke. New England Journal of Medicine 346(25), 19781988.

Boustan, L. P., M. E. Kahn, and P. W. Rhode (2012). Moving to higher ground: Migration response to natural disasters in the early twentieth century. American Economic Review 102(3), 238-44.

Buckles, K. S. and D. M. Hungerman (2013). Season of birth and later outcomes: Old questions, new answers. Review of Economics and Statistics 95(3), 711-724.

Burgess, R., O. Deschenes, D. Donaldson, and M. Greenstone (2013). The unequal effects of weather and climate change: Evidence from mortality in india. Unpublished working paper.

Burke, M. and K. Emerick (2016). Adaptation to climate change: Evidence from us agriculture. American Economic Journal: Economic Policy 8(3), 106-40.

Chand, T. K., K. Badarinath, C. Elvidge, and B. Tuttle (2009). Spatial characterization of electrical power consumption patterns over india using temporal dmsp-ols night-time satellite data. International Journal of Remote Sensing 30(3), 647-661.

Chay, K. Y. and M. Greenstone (2000). The convergence in black-white infant mortality rates during the 1960's. The American Economic Review 90(2), 326-332.

Chen, A., E. Oster, and H. Williams (2016, May). Why is infant mortality higher in the united states than in europe? American Economic Journal: Economic Policy 8(2), 89-124. 
Chen, M. A. and G. Raveendran (2012). Urban employment in india: Recent trends and patterns. Margin: The Journal of Applied Economic Research 6(2), 159-179.

Costello, A., M. Abbas, A. Allen, S. Ball, S. Bell, R. Bellamy, S. Friel, N. Groce, A. Johnson, M. Kett, et al. (2009). Managing the health effects of climate change. The Lancet 373(9676), 1693-1733.

Currie, J. and O. Deschênes (2016). Children and climate change: Introducing the issue. The Future of Children 26(1), 3-9.

Dadvand, P., X. Basagaña, C. Sartini, F. Figueras, M. Vrijheid, A. De Nazelle, J. Sunyer, and M. J. Nieuwenhuijsen (2011). Climate extremes and the length of gestation. Environmental health perspectives 119(10), 1449.

Dasgupta, A. (2013). Can the major public works policy buffer negative shocks in early childhood?: evidence from Andhra Pradesh, India.

DeFranco, E. A., L. M. Seske, J. M. Greenberg, and L. J. Muglia (2015). Influence of interpregnancy interval on neonatal morbidity. American journal of obstetrics and gynecology 212(3), 386-e1.

Dell, M., B. F. Jones, and B. A. Olken (2014). What do we learn from the weather? the new climateeconomy literature. Journal of Economic Literature 52(3), 740-798.

Deryugina, T. and S. M. Hsiang (2014). Does the environment still matter? daily temperature and income in the united states. Technical report, National Bureau of Economic Research.

Deschenes, O. (2014). Temperature, human health, and adaptation: A review of the empirical literature. Energy Economics 46, 606-619.

Deschênes, O. and M. Greenstone (2011). Climate change, mortality, and adaptation: Evidence from annual fluctuations in weather in the us. American Economic Journal: Applied Economics 3(4), 152-85.

Deschênes, O., M. Greenstone, and J. Guryan (2009). Climate change and birth weight. The American Economic Review 99(2), 211-217.

Deschenes, O. and E. Moretti (2009). Extreme weather events, mortality, and migration. The Review of Economics and Statistics 91(4), 659-681.

Di Falco, S., M. Veronesi, and M. Yesuf (2011). Does adaptation to climate change provide food security? a micro-perspective from ethiopia. American Journal of Agricultural Economics 93(3), 829-846.

Fetzer, T. (2014). Social insurance and conflict: evidence from india. Job Market Paper, November 14.

Frankenberg, E., A. Buttenheim, B. Sikoki, and W. Suriastini (2009). Do women increase their use of reproductive health care when it becomes more available? evidence from indonesia. Studies in family planning 40(1), 27. 
Garg, T., M. Jagnani, and V. Taraz (2017). Human capital costs of climate change: Evidence from test scores in india. SSRN Electronic Journal.

Gonzalez, R. M. and D. Gilleskie (2017). Infant mortality rate as a measure of a countrys health: A robust method to improve reliability and comparability. Demography 54(2), 701-720.

Greenstone, M. and R. Hanna (2014). Environmental regulations, air and water pollution, and infant mortality in india. American Economic Review 104(10), 3038-72.

Gruber, J., N. Hendren, and R. M. Townsend (2014). The great equalizer: Health care access and infant mortality in thailand. American Economic Journal: Applied Economics 6(1), 91-107.

Guiteras, R. (2009). The impact of climate change on indian agriculture. Manuscript, Department of Economics, University of Maryland, College Park, Maryland.

Hanna, R. and P. Oliva (2016). Implications of climate change for children in developing countries. The Future of Children 26(1), 115-132.

Henderson, J. V., A. Storeygard, and D. N. Weil (2012). Measuring economic growth from outer space. The American Economic Review 102(2), 994-1028.

Hjort, J., M. Slvsten, and M. Wst (2017, October). Universal investment in infants and long-run health: Evidence from denmark's 1937 home visiting program. American Economic Journal: Applied Economics 9(4), 78-104.

Hoynes, H., D. W. Schanzenbach, and D. Almond (2016). Long-run impacts of childhood access to the safety net. The American Economic Review 106(4), 903-934.

Hsiang, S. M., M. Burke, and E. Miguel (2013). Quantifying the influence of climate on human conflict. Science 341(6151), 1235367.

Imbert, C. and J. Papp (2015). Labor market effects of social programs: Evidence from india's employment guarantee. American Economic Journal: Applied Economics 7(2), 233-63.

Isen, A., M. Rossin-Slater, and R. Walker (2015). Heat and long-run human capital formation. Unpublished Manuscript.

Iyer, L. and P. Topalova (2014). Poverty and crime: evidence from rainfall and trade shocks in india.

Jain, N., N. Srivastava, A. Khan, N. Dhar, S. Manon, V. Adhish, and D. Nandan (2008). Assessment of functioning of asha under nrhm in uttar pradesh. Health and Population: Perspectives and Issues 31(2), $132-140$.

Kazianga, H. and C. Udry (2006). Consumption smoothing? livestock, insurance and drought in rural burkina faso. Journal of Development economics 79(2), 413-446. 
Khanna, G. and L. Zimmermann (2014). Fighting maoist violence with promises: Evidence from indias employment guarantee scheme. The Economics of Peace and Security Journal 9(1).

Klonner, S. and C. Oldiges (2014). Safety net for india's poor or waste of public funds? poverty and welfare in the wake of the world's largest job guarantee program. Technical report, Discussion Paper Series, University of Heidelberg, Department of Economics.

Lakshminarayanan, S. and R. Jayalakshmy (2015). Diarrheal diseases among children in india: current scenario and future perspectives. Journal of natural science, biology, and medicine 6(1), 24.

Lam, D. A. and J. A. Miron (1996). The effects of temperature on human fertility. Demography 33(3), 291-305.

Lemoine, D. (2017). Expect above average temperatures: Identifying the economic impacts of climate change. Technical report, National Bureau of Economic Research.

Mansur, E. T., R. Mendelsohn, and W. Morrison (2008). Climate change adaptation: A study of fuel choice and consumption in the us energy sector. Journal of Environmental Economics and Management 55(2), 175-193.

Marchiori, L., J.-F. Maystadt, and I. Schumacher (2012). The impact of weather anomalies on migration in sub-saharan africa. Journal of Environmental Economics and Management 63(3), 355-374.

Miguel, E. (2005). Poverty and witch killing. The Review of Economic Studies 72(4), 1153-1172.

MOHFW (2009, May). Four years of nrhm 2005-09. Technical report.

Molina, O. and V. Saldarriaga (2016). The perils of climate change: In utero exposure to temperature variability and birth outcomes in the andean region.

Piehl, A. M., S. J. Cooper, A. A. Braga, and D. M. Kennedy (2003). Testing for structural breaks in the evaluation of programs. Review of Economics and Statistics 85(3), 550-558.

Rao, T. (2014). The impact of a community health worker program on childhood immunization: Evidence from india's' asha'workers. Available at SSRN 2444391.

Reidpath, D. D. and P. Allotey (2003). Infant mortality rate as an indicator of population health. Journal of Epidemiology \& Community Health 57(5), 344-346.

Rose, E. (1999). Consumption smoothing and excess female mortality in rural india. Review of Economics and statistics 81(1), 41-49.

Rosenzweig, M. R. and K. I. Wolpin (1993). Credit market constraints, consumption smoothing, and the accumulation of durable production assets in low-income countries: Investments in bullocks in india. Journal of political economy 101(2), 223-244. 
Santangelo, G. (2016). Firms and farms: The impact of agricultural productivity on the local indian economy.

Sekhri, S. and A. Storeygard (2014). Dowry deaths: Response to weather variability in india. Journal of development economics 111, 212-223.

Shah, M. and B. M. Steinberg (2017). Drought of opportunities: Contemporaneous and long-term impacts of rainfall shocks on human capital. Journal of Political Economy 125(2), 527-561.

Soultanakis-Aligianni, H. N. (2003). Thermoregulation during exercise in pregnancy. Clinical obstetrics and gynecology 46(2), 442-455.

Townsend, R. M. (1994). Risk and insurance in village india. Econometrica: Journal of the Econometric Society, 539-591.

Wilde, J., B. Apouey, T. Jung, et al. (2014). Heat waves at conception and later life outcomes. Unpublished Manuscript.

Wüst, M. (2012). Early interventions and infant health: Evidence from the danish home visiting program. Labour Economics 19(4), 484-495. 


\section{Tables and Figures}

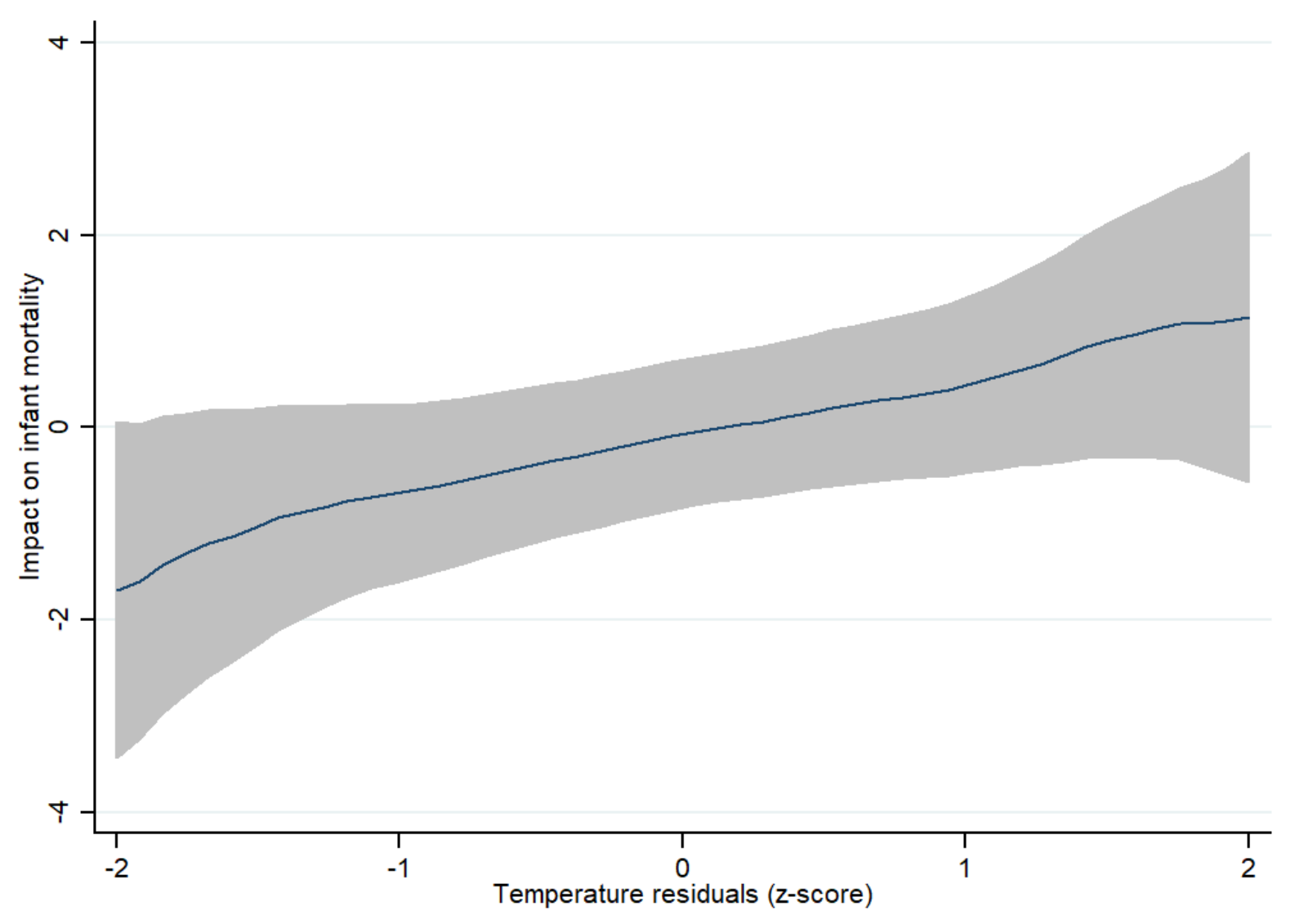

Figure 1: Local regressions of infant mortality on z-score of CDD exceeding 90F in utero and birth month in rural India 


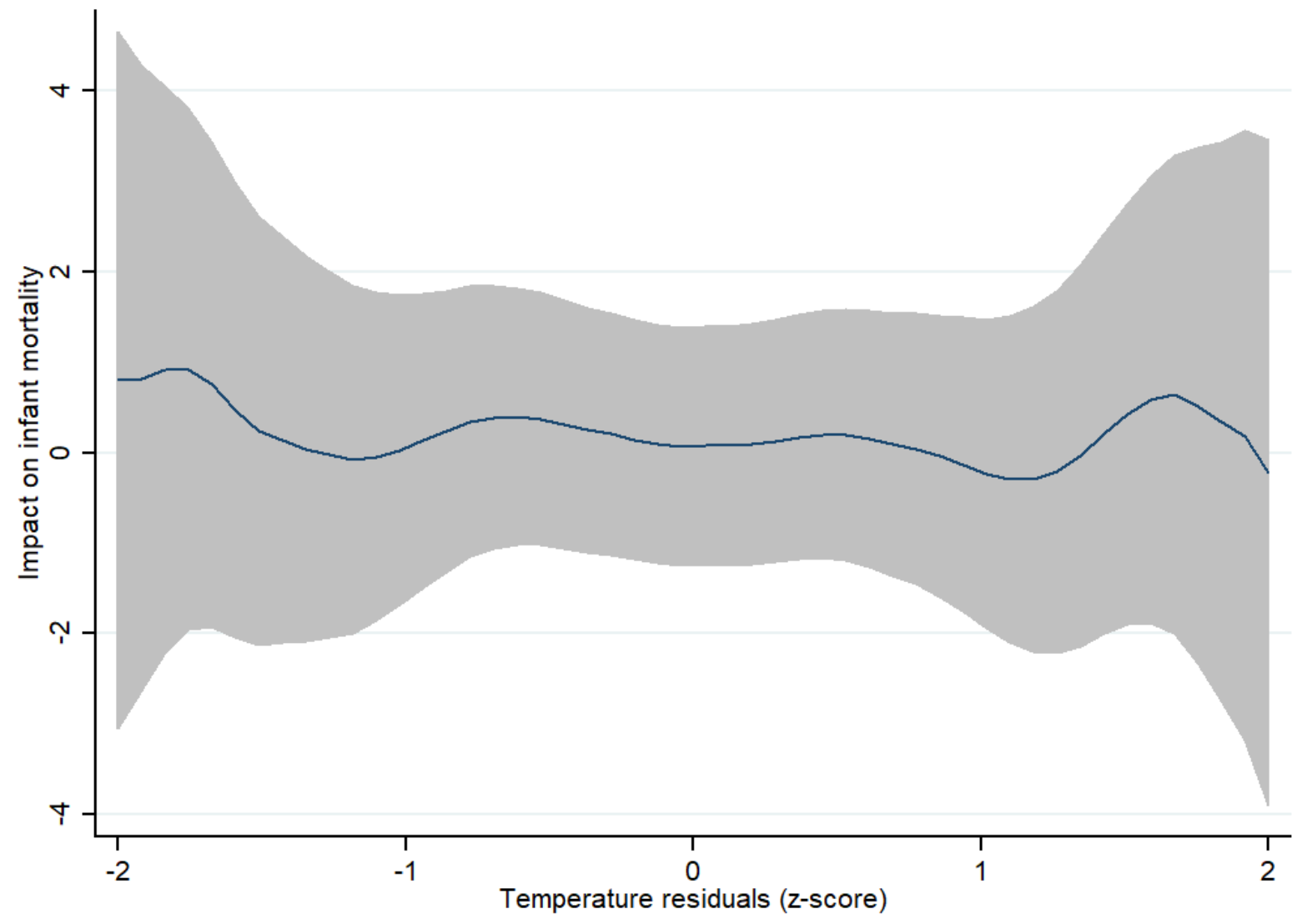

Figure 2: Local regressions of infant mortality on z-score of CDD exceeding 90F in utero and birth month in urban India 
Table 1: Summary statistics

Rural $(\mathrm{N}=397,324) \quad$ Urban $(\mathrm{N}=123,863)$

Dependent Variable

Infant Mortality (per 1000 births)

54.33

42.69

Weather Variables

Number of days exceeding 90F during Birth Month

2.15

2.22

CDD exceeding 90F in utero and Birth Month

85.86

83.91

Average Monthly Precipitation during pregnancy (in $\mathrm{mm}$ )

100.18

95.11

Demographic Characteristics

Number of Boys (per 1000 births)

520.69

524.69

Mother Years of Schooling

3.16

6.46

Mother Age in Years

27.06

27.47

Hindu

$77.2 \%$

$70.1 \%$

Muslim

$11.9 \%$

$21.1 \%$

Christian

$5.9 \%$

$4.9 \%$

Sikh

$1.9 \%$

$1.5 \%$

Buddhist

$1.5 \%$

$0.8 \%$

Jain

$0.0 \%$

$0.7 \%$ 
Table 2: Effect of temperature in utero on infant mortality

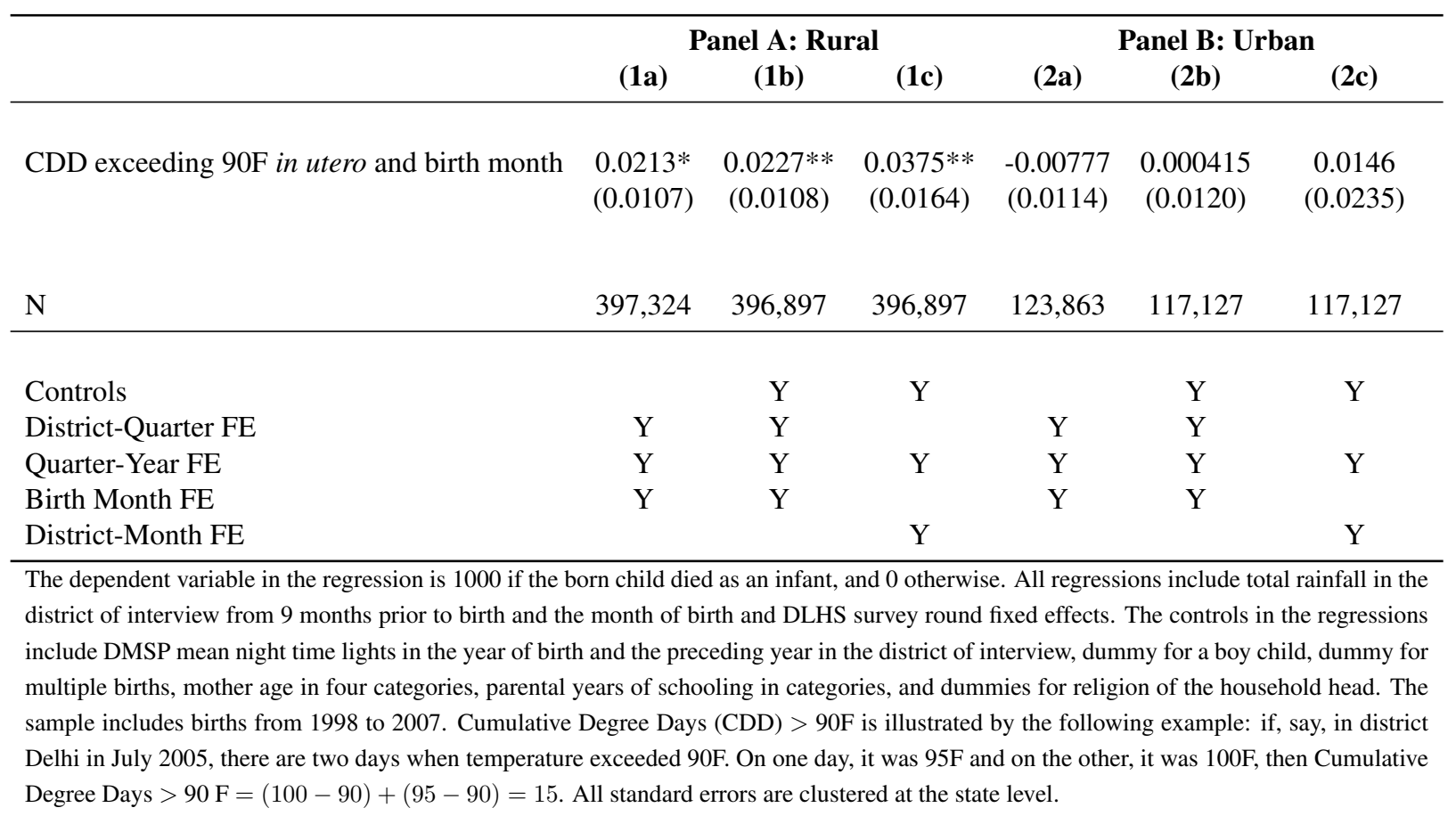


Table 3: Effect of temperature in utero on infant mortality (Robustness)

\begin{tabular}{|c|c|c|c|c|}
\hline \multirow{3}{*}{ CDD exceeding 95F in utero and birth month } & \multicolumn{2}{|c|}{ Panel A: Rural } & \multicolumn{2}{|c|}{ Panel B: Urban } \\
\hline & (1a) & (1b) & $(\mathbf{2 a})$ & $(2 \mathrm{~b})$ \\
\hline & $\begin{array}{c}0.0792 * * * \\
(0.0271)\end{array}$ & $\begin{array}{c}0.0931 * * * \\
(0.0322)\end{array}$ & $\begin{array}{l}0.00790 \\
(0.0338)\end{array}$ & $\begin{array}{c}0.0484 \\
(0.0403)\end{array}$ \\
\hline $\mathrm{N}$ & 396,897 & 396,897 & 117,127 & 117,127 \\
\hline CDD exceeding 92F in utero and birth month & $\begin{array}{c}0.0373 * * \\
(0.0161)\end{array}$ & $\begin{array}{c}0.0552 * * \\
(0.0224)\end{array}$ & $\begin{array}{l}0.00433 \\
(0.0144)\end{array}$ & $\begin{array}{c}0.0273 \\
(0.0250)\end{array}$ \\
\hline $\mathrm{N}$ & 396,897 & 396,897 & 117,127 & 117,127 \\
\hline CDD exceeding $87 \mathrm{~F}$ in utero and birth month & $\begin{array}{c}0.0105 \\
(0.00676)\end{array}$ & $\begin{array}{c}0.0182 \\
(0.0114)\end{array}$ & $\begin{array}{c}0.000208 \\
(0.0102)\end{array}$ & $\begin{array}{c}0.00933 \\
(0.0201)\end{array}$ \\
\hline $\mathrm{N}$ & 396,897 & 396,897 & 117,127 & 117,127 \\
\hline CDD exceeding $85 \mathrm{~F}$ in utero and birth month & $\begin{array}{c}0.00619 \\
(0.00534)\end{array}$ & $\begin{array}{c}0.0105 \\
(0.00933)\end{array}$ & $\begin{array}{c}-0.000338 \\
(0.00851)\end{array}$ & $\begin{array}{c}0.00666 \\
(0.0161)\end{array}$ \\
\hline $\mathrm{N}$ & 396,897 & 396,897 & 117,127 & 117,127 \\
\hline Controls & $\mathrm{Y}$ & $\mathrm{Y}$ & $\mathrm{Y}$ & Y \\
\hline District-Quarter FE & Y & & $\mathrm{Y}$ & \\
\hline Quarter-Year FE & $\mathrm{Y}$ & Y & $\mathrm{Y}$ & $\mathrm{Y}$ \\
\hline Birth Month FE & Y & & $\mathrm{Y}$ & \\
\hline District-Month FE & & Y & & $\mathrm{Y}$ \\
\hline
\end{tabular}

The dependent variable in the regression is 1000 if the born child died as an infant, and 0 otherwise. The controls in the regressions include total rainfall in the district of interview from 9 months prior to birth and month of birth, DMSP mean night time lights in the year of birth and the preceding year in the district of interview, DLHS survey round fixed effects, dummy for a boy child, dummy for multiple births, mother age in four categories, parental years of schooling in categories, and dummies for religion of the household head. The sample includes births from 1998 to 2007. Cumulative Degree Days (CDD) > $90 \mathrm{~F}$ is illustrated by the following example, if, say, in district Delhi in July 2005, there are two days when temperature exceeded 90F. On one day, it was 95F and on the other, it was $100 \mathrm{~F}$, then Cumulative Degree Days $>90 \mathrm{~F}=(100-90)+(95-90)=15$. All standard errors are clustered at the state level. 
Table 4: Effect of temperature in utero on infant mortality (Mother and Household FE)

\begin{tabular}{|c|c|c|}
\hline & Household FE & Mother FE \\
\hline CDD exceeding $90 \mathrm{~F}$ in utero and birth month & $\begin{array}{c}0.0352 * * \\
(0.0152)\end{array}$ & $\begin{array}{c}0.0364 * * \\
(0.0145)\end{array}$ \\
\hline $\mathrm{N}$ & 200,488 & 180,252 \\
\hline Controls & $\mathrm{Y}$ & $\mathrm{Y}$ \\
\hline District-Quarter FE & $\mathrm{Y}$ & $\mathrm{Y}$ \\
\hline Quarter-Year FE & $\mathrm{Y}$ & $\mathrm{Y}$ \\
\hline Birth Month FE & $\mathrm{Y}$ & $\mathrm{Y}$ \\
\hline Household FE & $\mathrm{Y}$ & \\
\hline Mother FE & & Y \\
\hline \multicolumn{3}{|c|}{$\begin{array}{l}\text { Only rural sample is considered where multiple births have taken place within a household or to a mother in our } \\
\text { sample period. The dependent variable in the regression is } 1000 \text { if the born child died as an infant, and } 0 \text { otherwise. } \\
\text { The controls in the regressions include total rainfall in the district of interview from } 9 \text { months prior to birth and } \\
\text { month of birth, DMSP mean night time lights in the year of birth and the preceding year in the district of interview, } \\
\text { DLHS survey round fixed effects, dummy for a boy child, dummy for multiple births, mother age in four categories, } \\
\text { parental years of schooling in categories, and dummies for religion of the household head. The sample includes } \\
\text { births from } 1998 \text { to } 2007 \text {. Cumulative Degree Days (CDD) }>90 \mathrm{~F} \text { is illustrated by the following example: if, say, } \\
\text { in district Delhi in July } 2005 \text {, there are two days when temperature exceeded } 90 \mathrm{~F} \text {. On one day, it was } 95 \mathrm{~F} \text { and on } \\
\text { the other, it was } 100 \mathrm{~F} \text {, then Cumulative Degree Days }>90 \mathrm{~F}=(100-90)+(95-90)=15 \text {. All standard errors } \\
\text { are clustered at the state level. }\end{array}$} \\
\hline
\end{tabular}


Table 5: Effect of temperature on yield (Kharif season only)

\begin{tabular}{lccc}
\hline & Rice & Bajra & Cotton \\
\hline $\begin{array}{l}\text { CDD }>90 \mathrm{~F} \\
\text { during sowing and harvesting }\end{array}$ & $-.0003^{*}$ & $-.0012 * * *$ & $-.0013^{* * *}$ \\
& $(.0001)$ & $(.0003)$ & $(.0003)$ \\
$\begin{array}{l}\text { Mean rainfall } \\
\text { during sowing and harvesting }\end{array}$ & $.0004 * * *$ & $.0002 * * *$ & $.0005^{* * *}$ \\
\hline $\mathrm{N}$ & $(.0000)$ & $(.0000)$ & $(.0001)$ \\
\hline \hline & 4809 & 3214 & 2611 \\
\hline $\mathrm{CDD}>90 \mathrm{~F}$ & Soyabean & Groundnut & Jowar \\
during sowing and harvesting & $-.0009 * * *$ & $-.0004 *$ & $-.0010 * * *$ \\
& $(.0003)$ & $(.0002)$ & $(.0004)$ \\
$\begin{array}{l}\text { Mean rainfall } \\
\text { during sowing and harvesting }\end{array}$ & $.0001 * * *$ & $.0004 * * *$ & $.0002 * * *$ \\
\hline $\mathrm{N}$ & $(.0000)$ & $(.0000)$ & $(.0000)$ \\
\hline \hline
\end{tabular}

The dependent variable is logarithm of yield (defined as production/area) of each variety of crops. All the regressions control for fixed effects for district and year. The sample covers 1998 till 2010. The season of sowing and harvesting kharif crops is considered from May to October. Standard Errors are clustered at the district level. 
Table 6: Effect of temperature on incidence of illness

\begin{tabular}{lccc}
\hline & Diarrhea & Fever & Cough \\
\hline & & & \\
CDD exceeding 90F in utero and birth month & 0.0762 & 0.0237 & -0.00161 \\
& $(0.0499)$ & $(0.0405)$ & $(0.0353)$ \\
CDD exceeding 90F in the month of interview & & & \\
& $0.170 * *$ & $0.227 *$ & $0.343 * * *$ \\
CDD exceeding 90F in the preceding month of interview & 0.208 & 0.203 & $0.391 * *$ \\
& $(0.150)$ & $(0.135)$ & $(0.144)$ \\
& & & \\
Joint Significance (Prob $>$ F) & 0.0176 & 0.1501 & 0.0079 \\
Mean of dependent variable & 119 & 201 & 204 \\
N & 253,525 & 253,762 & 253,716 \\
\hline
\end{tabular}

The dependent variable in the regression is 1000 if the child suffered from an illness in the past two weeks of interview, and 0 otherwise. The controls in the regressions include district rainfall in the current and previous month of interview, rainfall during pregnancy, DMSP mean night time lights in the present and previous year of interview at the district level, mother age, parental schooling, urban dummy, dummy if the child is a boy, dummies for religion of the household head, and dummies for housing not of brick and mortar and below-poverty line card holder. The regressions also control for fixed effects of district by birth quarter, interview month by year, birth year by quarter, and birth month. The sample is confined to wave 3 of DLHS so that all the babies are born after 2003. Cumulative Degree Days (CDD) > $90 \mathrm{~F}$ is illustrated by the following example: if, say, in district Delhi in July 2005 , there are two days when temperature exceeded 90F. On one day, it was $95 \mathrm{~F}$ and on the other, it was $100 \mathrm{~F}$, then Cumulative Degree Days $>90 \mathrm{~F}=(100-90)+(95-90)=15$. All standard errors are clustered at the state level. 
Table 7: Mitigation of heat-induced infant mortality due to prenatal exposure to ASHA and NREGA

\begin{tabular}{|c|c|c|c|c|c|c|c|}
\hline & $\begin{array}{c}\text { Infant } \\
\text { mortality } \\
\text { (1) }\end{array}$ & $\begin{array}{c}\text { Infant } \\
\text { mortality } \\
\text { (2) }\end{array}$ & $\begin{array}{c}\text { Infant } \\
\text { mortality } \\
\text { (3) }\end{array}$ & $\begin{array}{c}\text { Infant } \\
\text { mortality } \\
\text { (4) }\end{array}$ & $\begin{array}{c}\text { Infant } \\
\text { mortality } \\
\text { (5) }\end{array}$ & $\begin{array}{c}\text { Infant } \\
\text { mortality } \\
(6)\end{array}$ & $\begin{array}{c}\text { Infant } \\
\text { mortality } \\
(7)\end{array}$ \\
\hline ASHA X NREGA X CDD exceeding $90 \mathrm{~F}$ in utero and birth month & & & & & $\begin{array}{c}-0.0000703 \\
(0.000141)\end{array}$ & & $\begin{array}{l}-0.0000831 \\
(0.000133)\end{array}$ \\
\hline ASHA X CDD exceeding 90F in utero and birth month & $\begin{array}{c}-0.00228 * * \\
(0.00105)\end{array}$ & & $\begin{array}{l}-0.00249 * \\
(0.00125)\end{array}$ & $\begin{array}{l}-0.00253^{*} \\
(0.00123)\end{array}$ & $\begin{array}{c}-0.00256^{*} \\
(0.00130)\end{array}$ & $\begin{array}{l}-0.00230^{*} \\
(0.00121)\end{array}$ & $\begin{array}{c}-0.00233^{*} \\
(0.00127)\end{array}$ \\
\hline NREGA X CDD exceeding $90 \mathrm{~F}$ in utero and birth month & & $\begin{array}{c}-0.00216^{* *} \\
(0.000843)\end{array}$ & $\begin{array}{l}0.000990 \\
(0.00142)\end{array}$ & $\begin{array}{c}0.00149 \\
(0.00136)\end{array}$ & $\begin{array}{c}0.00306 \\
(0.00183)\end{array}$ & $\begin{array}{c}0.00105 \\
(0.00124)\end{array}$ & $\begin{array}{c}0.00281 \\
(0.00178)\end{array}$ \\
\hline CDD exceeding $90 \mathrm{~F}$ in utero and birth month & $\begin{array}{c}0.0219 * * \\
(0.0102)\end{array}$ & $\begin{array}{l}0.0196^{*} \\
(0.0105)\end{array}$ & $\begin{array}{c}0.0217^{* * *} \\
(0.0103)\end{array}$ & $\begin{array}{c}0.0225^{* *} * \\
(0.0108)\end{array}$ & $\begin{array}{c}0.0228 * * \\
(0.0106)\end{array}$ & $\begin{array}{c}0.0272 \\
(0.0189)\end{array}$ & $\begin{array}{c}0.0282 \\
(0.0186)\end{array}$ \\
\hline $\begin{array}{l}\text { N } \\
\text { Joint Significance of ASHA and NREGA mitigation variables (Prob > F) }\end{array}$ & 356,205 & 356,205 & $\begin{array}{l}356,205 \\
0.0614\end{array}$ & $\begin{array}{c}356,205 \\
0.098\end{array}$ & $\begin{array}{l}356,205 \\
0.1037\end{array}$ & $\begin{array}{l}356,205 \\
0.1185\end{array}$ & $\begin{array}{c}356,205 \\
0.1658\end{array}$ \\
\hline $\begin{array}{l}\text { Individual Controls } \\
\text { District-Quarter FE } \\
\text { Quarter-Year FE } \\
\text { Birth Month FE } \\
\text { District-Month FE }\end{array}$ & $\begin{array}{l}\mathrm{Y} \\
\mathrm{Y} \\
\mathrm{Y}\end{array}$ & $\begin{array}{l}\mathrm{Y} \\
\mathrm{Y} \\
\mathrm{Y}\end{array}$ & $\begin{array}{l}\mathrm{Y} \\
\mathrm{Y} \\
\mathrm{Y}\end{array}$ & $\begin{array}{l}\mathrm{Y} \\
\mathrm{Y} \\
\mathrm{Y} \\
\mathrm{Y}\end{array}$ & $\begin{array}{l}\mathrm{Y} \\
\mathrm{Y} \\
\mathrm{Y} \\
\mathrm{Y}\end{array}$ & $\begin{array}{l}\mathrm{Y} \\
\mathrm{Y} \\
\mathrm{Y}\end{array}$ & $\begin{array}{l}\mathrm{Y} \\
\mathrm{Y} \\
\mathrm{Y}\end{array}$ \\
\hline \multicolumn{8}{|c|}{$\begin{array}{l}\text { Only rural sample is considered. The dependent variable in the regression is } 1000 \text { if the born child died as an infant, and } 0 \text { otherwise. ASHA represents the months of exposure to the program since } \\
\text { it started in a district till a child is born, and takes the value } 0 \text { otherwise. The variable NREGA is defined similarly. All regressions include the direct impacts of ASHA and NREGA, total rainfall } \\
\text { in the district of interview from } 9 \text { months prior to birth and month of birth, DLHS survey round fixed effects, and state level yearly controls including number of females per } 1,000 \text { males, percentage } \\
\text { of women literate, percentage of population living in urban area, logarithm of of per capita real net state domestic product (in } 2004-05 \text { Rupees), public health expenditure as percentage of state GDP, } \\
\text { own tax revenue as percentage of state GDP, logarithm of aggregate government expenses excluding public health expenses, logarithm of social expenditure excluding public health expenses, and per } \\
\text { capita real public health expenses (in 2004-05 Rupees). Individual controls include DMSP mean night time lights in the year of birth and the preceding year in the district of interview, dummy for a } \\
\text { boy child, dummy for multiple births, mother age in four categories, parental years of schooling in categories, and dummies for religion of the household head. The sample includes births from } 1998 \\
\text { to } 2007 \text {. Cumulative Degree Days (CDD) }>90 \mathrm{~F} \text { is illustrated by the following example: if, say, in district Delhi in July } 2005 \text {, there are two days when temperature exceeded } 90 \mathrm{~F} \text {. On one day, it was } \\
95 \mathrm{~F} \text { and on the other, it was } 100 \mathrm{~F} \text {, then Cumulative Degree Days }>90 \mathrm{~F}=(100-90)+(95-90)=15 \text {. All standard errors are clustered at the state level. }\end{array}$} \\
\hline
\end{tabular}




\section{Appendix}

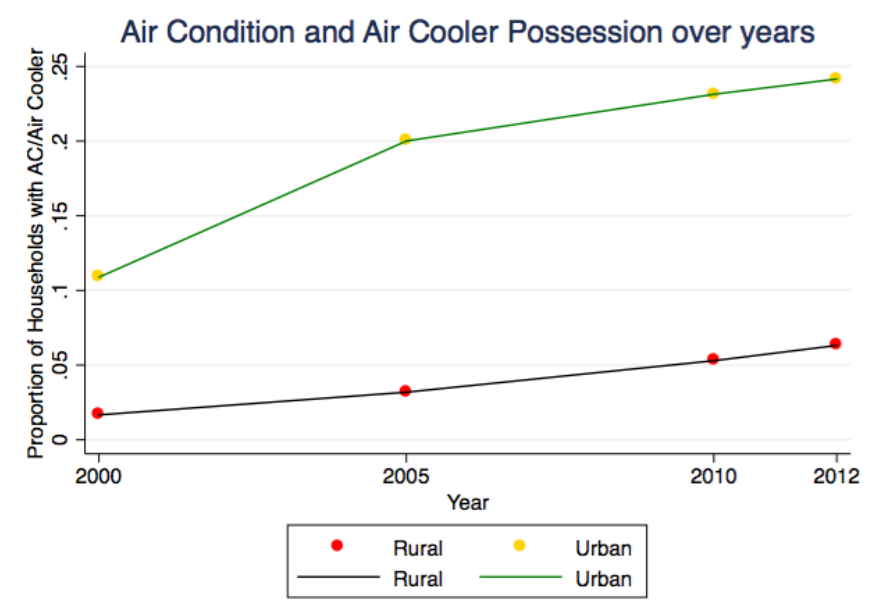

Figure A1: Calculated from the National Sample Survey's (NSS) consumption survey, using the $55,61,66$, and $68^{\text {th }}$ rounds

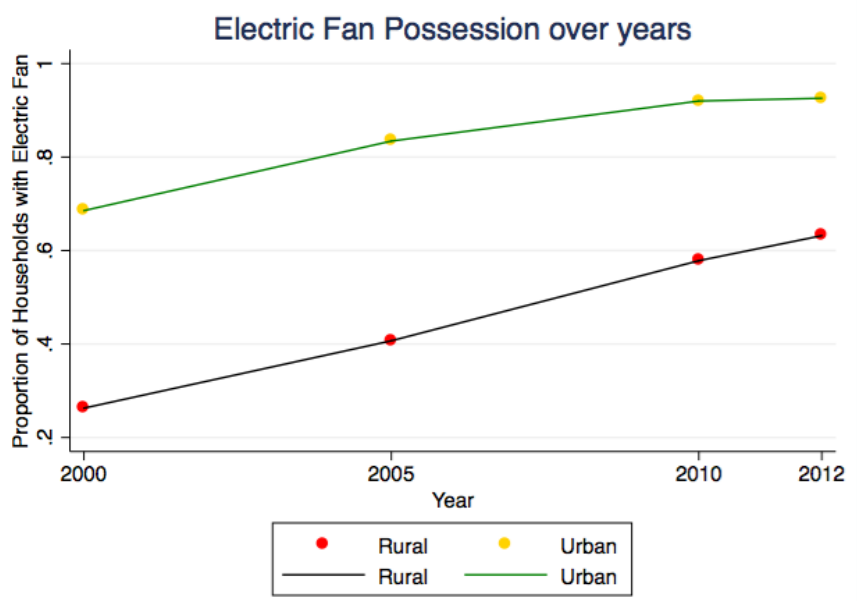

Figure A2: Calculated from the National Sample Survey's (NSS) consumption survey, using the $55,61,66$, and $68^{\text {th }}$ rounds 


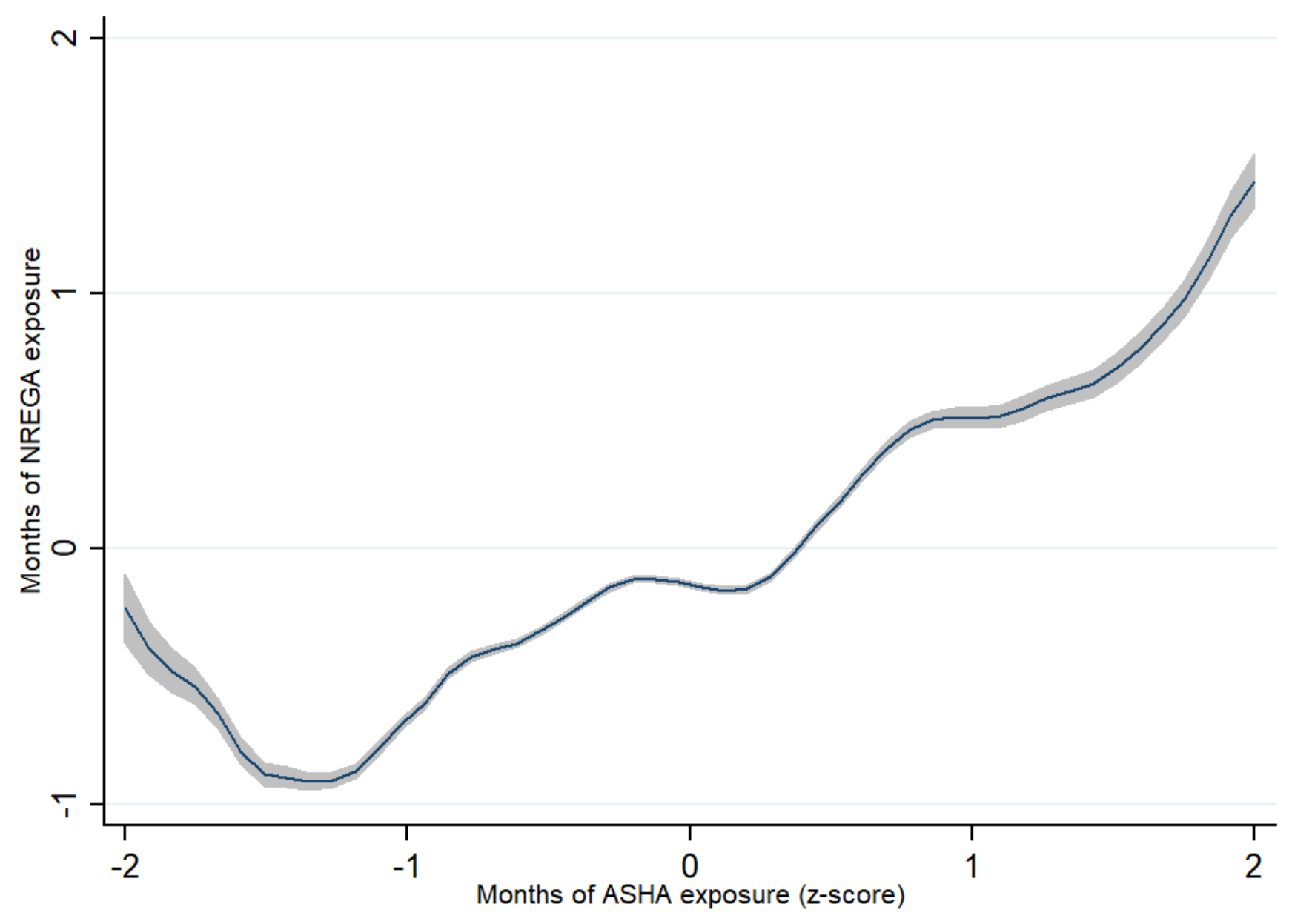

Figure A3: Association between ASHA and NREGA exposure 


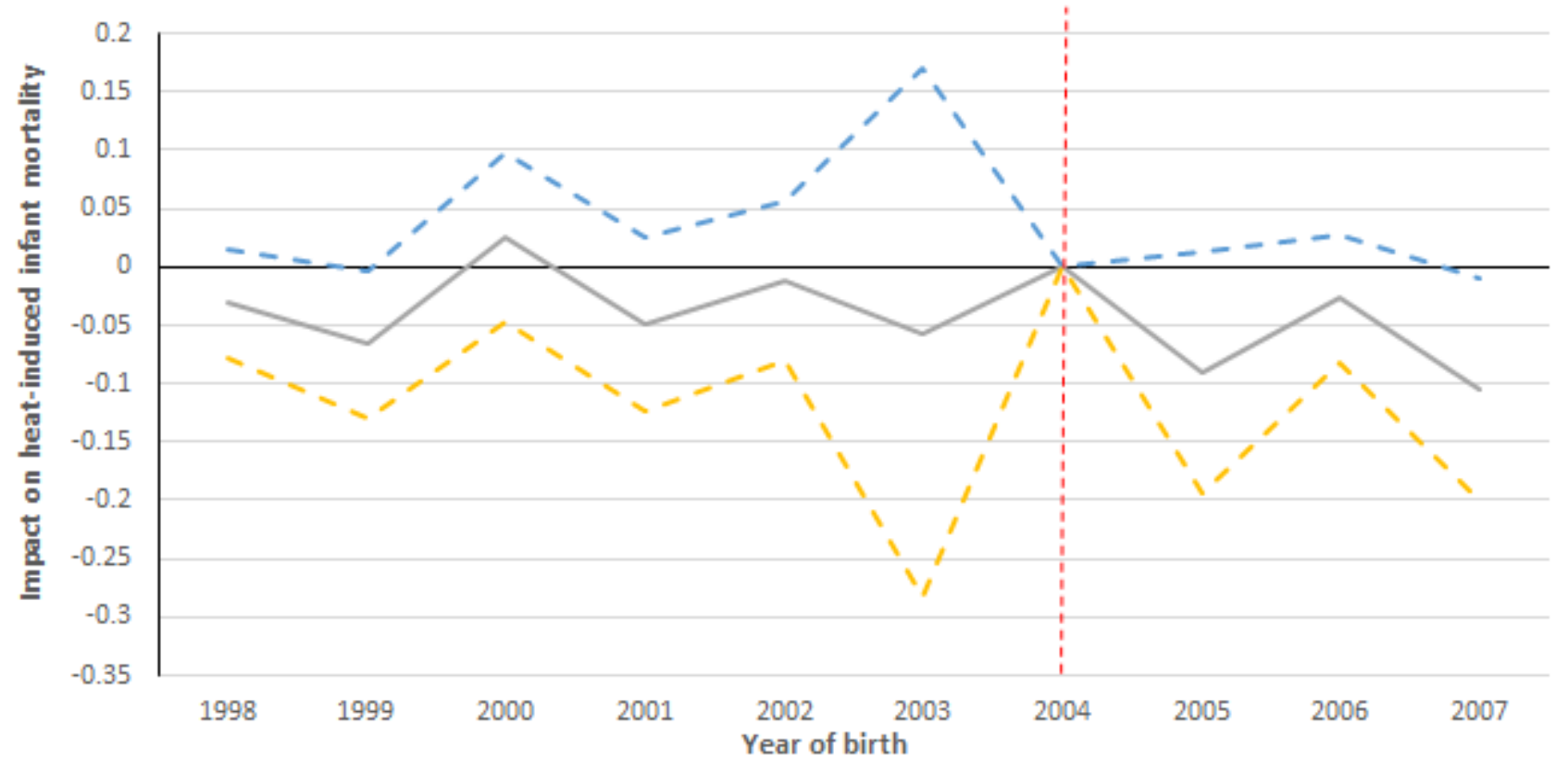

Figure A4: Year by year mitigation of heat-induced infant mortality due to ASHA 


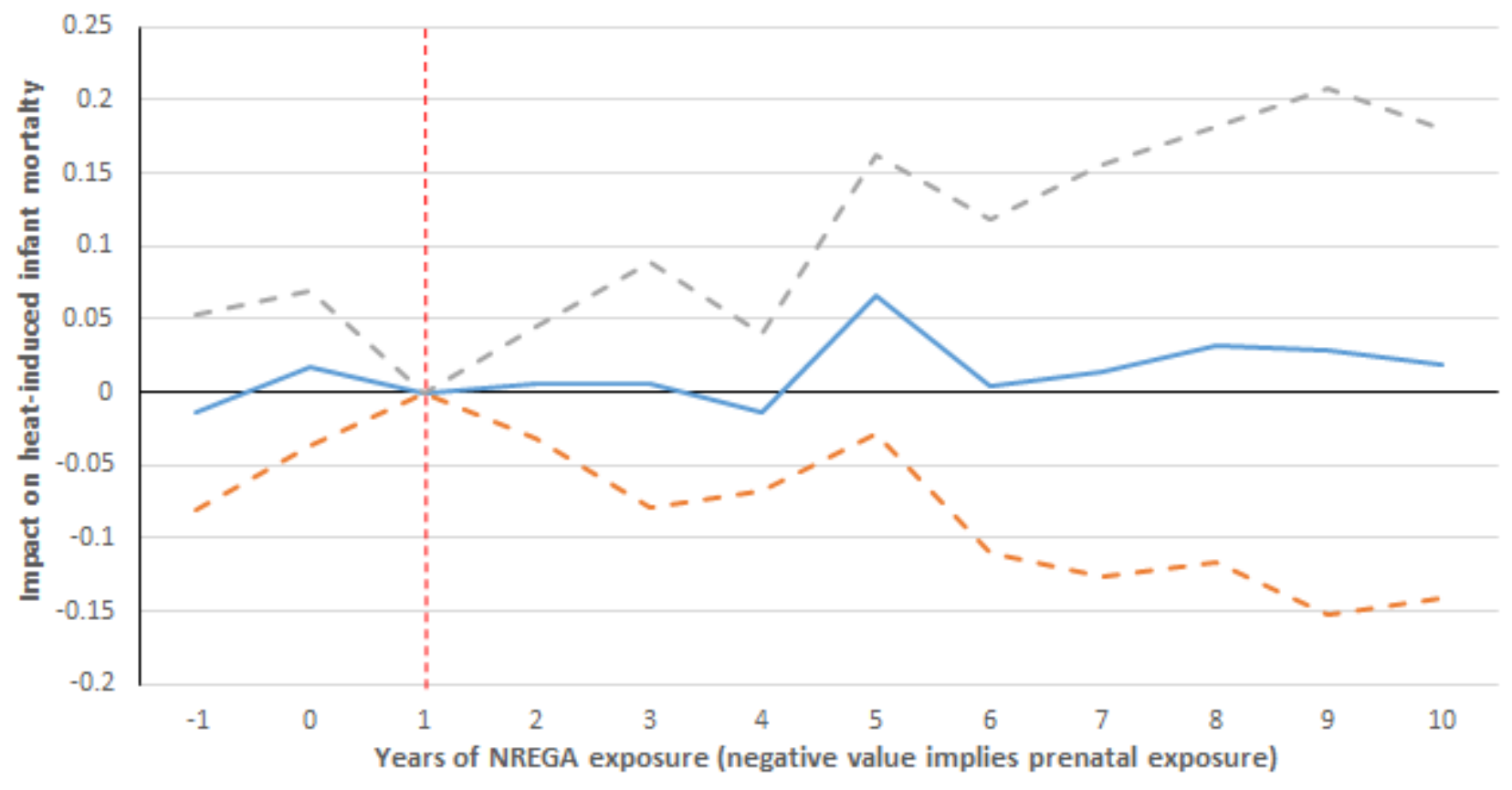

Figure A5: Year by year mitigation of heat-induced infant mortality due to NREGA 


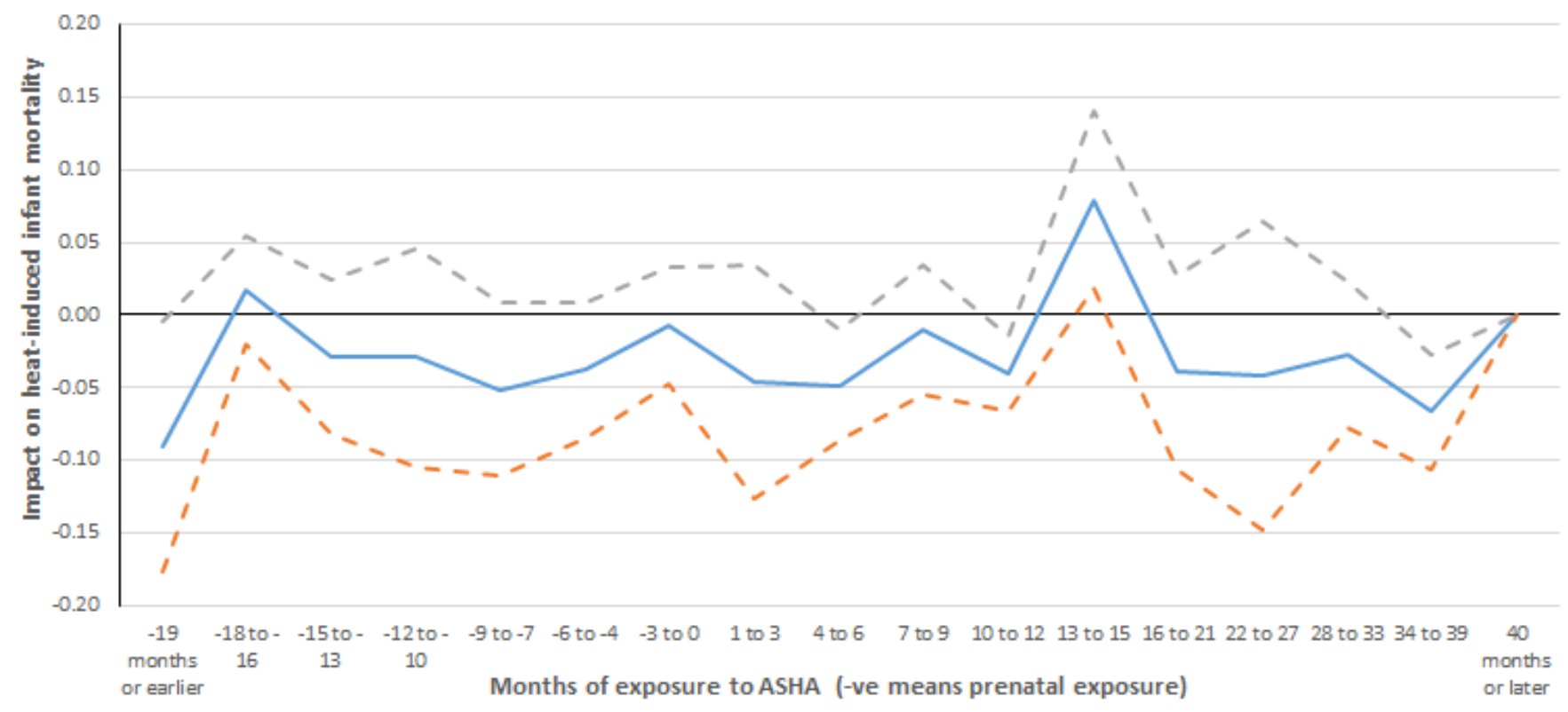

Figure A6: Event study estimates of the impact of ASHA exposure on heat-induced infant mortality 


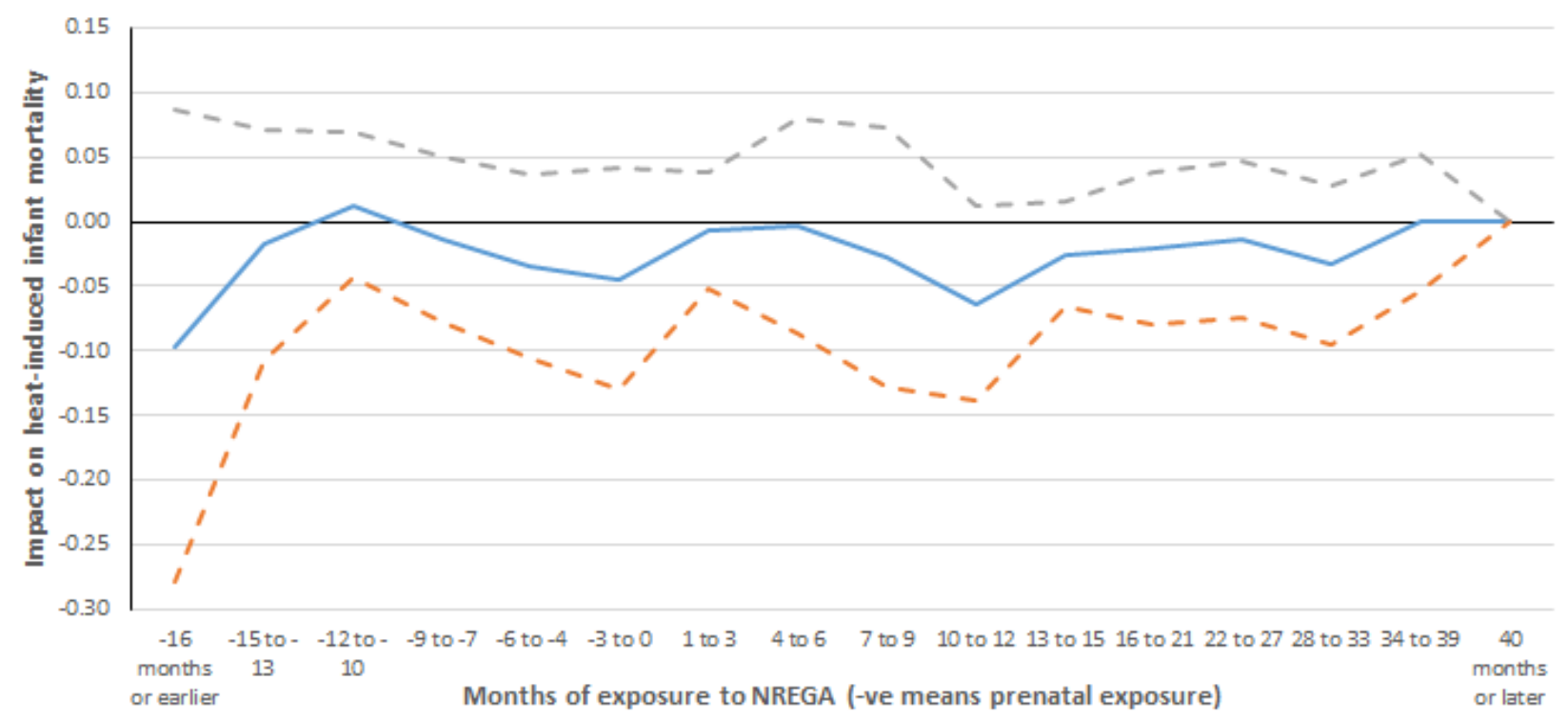

Figure A7: Event study estimates of the impact of NREGA exposure on heat-induced infant mortality 
Table A1: Effect of temperature on infant mortality: alternative specification

\section{Infant mortality Infant mortality}

CDD exceeding 90F in utero and birth month $\quad 0.0213^{*}$

$(0.0107)$

$0.0261 *$

$(0.0137)$

$\mathrm{N}$

397,324

397,324

\section{District-Quarter FE}

Y

Quarter-Year FE

Birth Month FE

Y

Y

District-Quarter-Year FE

$\mathrm{Y}$

Only rural sample is considered. The dependent variable in the regression is 1000 if the born child died as an infant, and 0 otherwise. No child or parental level controls are added. The first column is reproduced from column 1a in Table 2. The regression in the second column controls for total rainfall in the district of interview from 9 months prior to birth and month of birth and DLHS survey round fixed effects. The sample includes births from 1998 to 2007. Cumulative Degree Days (CDD) > $90 \mathrm{~F}$ is illustrated by the following example: if, say, in district Delhi in July 2005, there are two days when temperature exceeded 90F. On one day, it was 95F and on the other, it was 100F, then Cumulative Degree Days $>90 \mathrm{~F}=$ $(100-90)+(95-90)=15$. All standard errors are clustered at the state level. 


\section{Table A2: Heterogeneity of effects of temperature}

\begin{tabular}{|c|c|c|c|c|}
\hline & Birth Order & Mother Years of Schooling & Malaria -prone Areas & Mother Age \\
\hline CDD exceeding $90 \mathrm{~F}$ in utero and birth month & $\begin{array}{c}0.0133 \\
(0.0129)\end{array}$ & $\begin{array}{c}0.0309 * * \\
(0.0112)\end{array}$ & $\begin{array}{l}0.0220 * * \\
(0.00995)\end{array}$ & $\begin{array}{c}0.0245^{* *} * \\
(0.0106)\end{array}$ \\
\hline Birth Order $1 \mathrm{X}$ CDD exceeding $90 \mathrm{~F}$ in utero and birth month & $\begin{array}{c}0.0195 \\
(0.0121)\end{array}$ & & & \\
\hline Birth Order $2 \mathrm{X}$ CDD exceeding $90 \mathrm{~F}$ in utero and birth month & $\begin{array}{c}0.0194 \\
(0.0117)\end{array}$ & & & \\
\hline Mother Education (1-5 Yrs) X CDD exceeding 90F in utero and birth month & & $\begin{array}{c}-0.0262 * * * \\
(0.00756)\end{array}$ & & \\
\hline Mother Education (6-10 Yrs) X CDD exceeding 90F in utero and birth month & & $\begin{array}{c}-0.0325 * * * \\
(0.0106)\end{array}$ & & \\
\hline Mother Education (11 Yrs and above) X CDD exceeding 90F in utero and birth month & & $\begin{array}{c}-0.0218^{*} \\
(0.0127)\end{array}$ & & \\
\hline Malaria states X CDD exceeding 90F in utero and birth month & & & $\begin{array}{l}0.00656 \\
(0.0316)\end{array}$ & \\
\hline Mother age (31-40 Yrs) X CDD exceeding 90F in utero and birth month & & & & $\begin{array}{l}-0.00815 \\
(0.00686)\end{array}$ \\
\hline Mother age (41 Yrs and above) X CDD exceeding 90F in utero and birth month & & & & $\begin{array}{l}0.00593 \\
(0.0207)\end{array}$ \\
\hline $\mathrm{N}$ & 396,897 & 396,897 & 396,897 & 396,897 \\
\hline Controls & Y & Y & Y & Y \\
\hline District-Quarter FE & Y & Y & Y & $\mathrm{Y}$ \\
\hline Quarter-Year FE & $\mathrm{Y}$ & $\mathrm{Y}$ & $\mathrm{Y}$ & $\mathrm{Y}$ \\
\hline Birth Month FE & $\mathrm{Y}$ & $\mathrm{Y}$ & $\mathrm{Y}$ & $Y$ \\
\hline
\end{tabular}


Table A3: Effect of temperature on infant mortality in rural area, by hot and cold districts

\begin{tabular}{|c|c|c|c|c|c|c|}
\hline & \multicolumn{2}{|c|}{ Base } & \multicolumn{2}{|c|}{ Top third } & \multicolumn{2}{|c|}{ Bottom third } \\
\hline & (1a) & (1b) & (2a) & $(2 \mathrm{~b})$ & (3a) & $(3 \mathbf{b})$ \\
\hline CDD exceeding $90 \mathrm{~F}$ in utero and birth month & $\begin{array}{l}0.0227 * * \\
(0.0108)\end{array}$ & $\begin{array}{l}0.0375^{* *} \\
(0.0164)\end{array}$ & $\begin{array}{c}0.0189 \\
(0.0199)\end{array}$ & $\begin{array}{c}0.0309 \\
(0.0232)\end{array}$ & $\begin{array}{c}0.0556 \\
(0.0669)\end{array}$ & $\begin{array}{c}0.0733 \\
(0.0540)\end{array}$ \\
\hline $\begin{array}{l}\text { Mean of dependent variable } \\
\mathrm{N}\end{array}$ & $\begin{array}{c}54 \\
396,897\end{array}$ & $\begin{array}{c}54 \\
396,897\end{array}$ & $\begin{array}{c}58 \\
121,546\end{array}$ & $\begin{array}{c}58 \\
121,546\end{array}$ & $\begin{array}{c}47 \\
149,373\end{array}$ & $\begin{array}{c}47 \\
149,373\end{array}$ \\
\hline $\begin{array}{l}\text { Controls } \\
\text { District-Quarter FE } \\
\text { Quarter-Year FE } \\
\text { Birth Month FE } \\
\text { District-Month FE }\end{array}$ & $\begin{array}{l}\mathrm{Y} \\
\mathrm{Y} \\
\mathrm{Y} \\
\mathrm{Y}\end{array}$ & $\begin{array}{l}\mathrm{Y} \\
\mathrm{Y} \\
\mathrm{Y}\end{array}$ & $\begin{array}{l}\mathrm{Y} \\
\mathrm{Y} \\
\mathrm{Y} \\
\mathrm{Y}\end{array}$ & $\begin{array}{l}\mathrm{Y} \\
\mathrm{Y} \\
\mathrm{Y}\end{array}$ & $\begin{array}{l}\mathrm{Y} \\
\mathrm{Y} \\
\mathrm{Y} \\
\mathrm{Y}\end{array}$ & $\begin{array}{l}\mathrm{Y} \\
\mathrm{Y} \\
\mathrm{Y}\end{array}$ \\
\hline $\begin{array}{l}\text { Only rural sample is considered. The dependent variabl } \\
1 b \text { are reproduced from Table } 2 \text { (columns } 1 b \text { and } 1 c \text { resp } \\
\text { the latter are ranked by historical temperatures, from hi } \\
\text { bottom third of the states in that ranking. The controls } \\
\text { and month of birth, DMSP mean night time lights in th } \\
\text { effects, dummy for a boy child, dummy for multiple bir } \\
\text { religion of the household head. The sample includes bir } \\
\text { example: if, say, in district Delhi in July } 2005 \text {, there ar } \\
100 \mathrm{~F} \text {, then Cumulative Degree Days }>90 \mathrm{~F}=(100-9\end{array}$ & $\begin{array}{l}\text { in the regressi } \\
\text { ectively). In co } \\
\text { ghest to lowes } \\
\text { n the regressio } \\
\text { e year of birth } \\
\text { ths, mother age } \\
\text { ths from } 1998 \mathrm{t} \\
\text { e two days wh } \\
0)+(95-90\end{array}$ & $\begin{array}{l}\text { on is } 1000 \text { if } \mathrm{t} \\
\text { lumns } 2 a \text { and } \\
\text { t. The last twe } \\
\text { ns include tot. } \\
\text { and the prece } \\
\text { in four categ } \\
\text { 2007. Cum } \\
\text { en temperatur } \\
=15 \text {. All st }\end{array}$ & $\begin{array}{l}\text { born child d } \\
\text { the sample } \\
\text { lumns in th } \\
\text { infall in the } \\
\text { g year in th } \\
\text { s, parental } \\
\text { ive Degree I } \\
\text { xceeded } 90 \mathrm{~F}\end{array}$ & $\begin{array}{l}\text { d as an infan } \\
\text { restricted to } \\
\text { table corres } \\
\text { district of int } \\
\text { district of it } \\
\text { ears of schoo } \\
\text { ays (CDD) > } \\
\text { On one day, } \\
\text { clustered at }\end{array}$ & $\begin{array}{l}\text { nd } 0 \text { otherwise } \\
\text { top one-third } \\
\text { d to the samp } \\
\text { iew from } 9 \mathrm{mo} \\
\text { view, DLHS s } \\
\text { in categories } \\
\text { F is illustrate } \\
\text { vas } 95 \mathrm{~F} \text { and o }\end{array}$ & $\begin{array}{l}\text { Columns } 1 a \text { and } \\
\text { the states when } \\
\text { restricted to the } \\
\text { hs prior to birth } \\
\text { vey round fixed } \\
\text { nd dummies for } \\
\text { y the following } \\
\text { he other, it was }\end{array}$ \\
\hline
\end{tabular}

Table A4: Prenatal temperature and mother characteristics

\begin{tabular}{|c|c|c|c|c|}
\hline & Mother years of schooling & Mother years of schooling & Mother age (in years) & Mother age (in years) \\
\hline $\mathrm{CDD}$ exceeding $90 \mathrm{~F}$ in utero and birth month & $\begin{array}{c}-0.000317 \\
(0.000211)\end{array}$ & $\begin{array}{c}-0.000306 \\
(0.000325)\end{array}$ & $\begin{array}{l}0.000477^{*} \\
(0.000253)\end{array}$ & $\begin{array}{c}0.000488 \\
(0.000373)\end{array}$ \\
\hline $\mathrm{N}$ & 514,024 & 514,024 & 514,024 & 514,024 \\
\hline District-Quarter FE & $\mathrm{Y}$ & & $\mathrm{Y}$ & \\
\hline Quarter-Year FE & $\mathrm{Y}$ & $\mathrm{Y}$ & $\mathrm{Y}$ & $\mathrm{Y}$ \\
\hline Birth Month FE & $\mathrm{Y}$ & & $\mathrm{Y}$ & \\
\hline District-Month FE & & $\mathrm{Y}$ & & $\mathrm{Y}$ \\
\hline
\end{tabular}


Table A5: Temperature and number of births

(1a)

$-0.000535$

(0.00225)

CDD exceeding 90F in utero and birth month

0.00359

(0.00217)

51,028 (1b)

0.00199

(0.00364)

0.00231

(0.00238)

51,028
District-Quarter FE

Quarter-Year FE

Birth Month FE

District-Month FE

$\begin{array}{ll}\mathrm{Y} & \mathrm{Y} \\ \mathrm{Y} & \mathrm{Y}\end{array}$

The dependent variable is the total number of births in a district at month by year level. The controls in the regressions include total rainfall in the district of interview from 9 months prior to birth and month of birth, DMSP mean night time lights in the year of birth and the preceding year in the district of interview, and DLHS survey round fixed effects. Rainfall around conception i.e precipitation 10 months prior to birth is also separately controlled for. The sample includes births from 1998 to 2007. Cumulative Degree Days (CDD) $>90$ F is illustrated by the following example, if, say, in district Delhi in July 2005, there are two days when temperature exceeded 90F. On one day, it was 95F and on the other, it was 100F, then Cumulative Degree Days $>90 \mathrm{~F}=(100-90)+$ $(95-90)=15$. The regressions are weighted by sampling weights. All standard errors are clustered at the state level.

Table A6: Temperature and subsequent births 
Table A7: Effect of temperature on infant mortality (Robustness check)

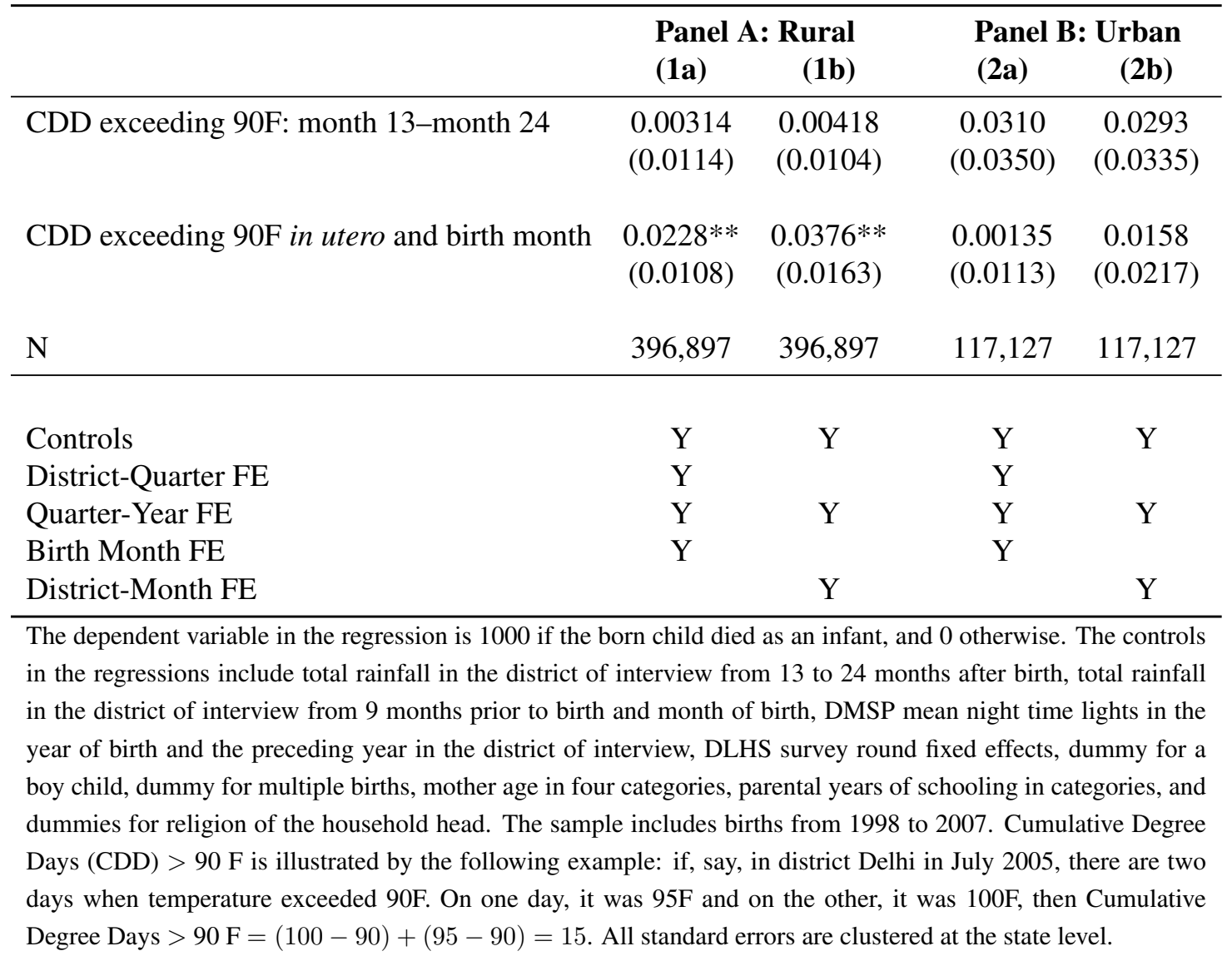

Table A8: Effect of temperature on real wages

\begin{tabular}{lcc}
\hline & $\begin{array}{c}\text { Logarithm of } \\
\text { real wage (male) } \\
(1)\end{array}$ & $\begin{array}{c}\text { Logarithm of } \\
\text { real wage (female) } \\
(2)\end{array}$ \\
\hline Summer CDD exceeding 90F & $-0.000250^{* *}$ & $-9.25 \mathrm{e}-05$ \\
& $(0.000110)$ & $(0.000116)$ \\
Monsoon CDD exceeding 90F & $7.97 \mathrm{e}-05$ & $8.10 \mathrm{e}-05$ \\
& $(0.000130)$ & $(0.000130)$ \\
Yearly Total Rain & $0.000142^{* * *}$ & $0.000150^{* * *}$ \\
& $(2.19 \mathrm{e}-05)$ & $(2.45 \mathrm{e}-05)$ \\
$\mathrm{N}$ & & \\
\hline
\end{tabular}

The dependent variables are logarithm of male and female wages. The regressions control for district FE and year FE. Summer includes the months of March, April, and May while Monsoon includes June to October. Standard Errors are clustered at the district level. 
Table A9: Effect of temperature on women crime

\begin{tabular}{|c|c|c|c|c|c|c|c|}
\hline & Rape & Kidnapping and abduction & Dowry deaths & Assault & Insult & Cruelty by husband's family & Importation of girls \\
\hline Yearly CDD exceeding 90F & $\begin{array}{c}0.00529 \\
(0.00964)\end{array}$ & $\begin{array}{c}0.0107 \\
(0.0116)\end{array}$ & $\begin{array}{l}-0.00416 \\
(0.00308)\end{array}$ & $\begin{array}{c}0.0188 \\
(0.0205)\end{array}$ & $\begin{array}{c}-0.00940 \\
(0.0333)\end{array}$ & $\begin{array}{c}0.134 \\
(0.0845)\end{array}$ & $\begin{array}{c}0.000935 \\
(0.000589)\end{array}$ \\
\hline Mean of dependent variable & 41.91 & 40.28 & 18.69 & 81.19 & 27.90 & 179.88 & 0.27 \\
\hline $\mathrm{N}$ & 4,193 & 4,193 & 4,193 & 4,193 & 4,193 & 4,193 & 4,193 \\
\hline
\end{tabular}

Table A10: Effect of temperature on conflicts

\begin{tabular}{lccccc}
\hline & Maoist & Islamic terrorism & Separatist & Total incidents & Others \\
\hline \multirow{2}{*}{ Yearly CDD exceeding 90F } & 0.00112 & -0.000108 & 0.000426 & 0.00144 & 0.00122 \\
& $(0.00158)$ & $(0.000205)$ & $(0.000403)$ & $(0.00166)$ & $(0.00174)$ \\
& & & & & 0.94 \\
Mean of dependent variable & 0.57 & 0.10 & 0.27 & 1.18 \\
$\mathrm{~N}$ & 4,756 & 4,756 & 4,756 & 4,756 & 4,756 \\
\hline
\end{tabular}

The dependent variables represent the number of incidents recorded at a district-year level between 2001 and 2008 . The regressions additionally control for yearly rainfall, DMSP mean night time lights in the year of birth and the preceding year in the district, and fixed effects for year and district. The regressions are weighted by the district population as of 2001 Census. Standard errors are clustered at the state level. 
Table A11: Mitigation of heat-induced infant mortality due to in utero exposure to ASHA and NREGA

\begin{tabular}{|c|c|c|c|c|c|c|c|}
\hline & $\begin{array}{c}\text { Infant } \\
\text { mortality } \\
\text { (1) }\end{array}$ & $\begin{array}{c}\text { Infant } \\
\text { mortality } \\
\text { (2) }\end{array}$ & $\begin{array}{c}\text { Infant } \\
\text { mortality } \\
\text { (3) }\end{array}$ & $\begin{array}{c}\text { Infant } \\
\text { mortality } \\
\text { (4) }\end{array}$ & $\begin{array}{c}\text { Infant } \\
\text { mortality } \\
(5)\end{array}$ & $\begin{array}{c}\text { Infant } \\
\text { mortality } \\
(6)\end{array}$ & $\begin{array}{c}\text { Infant } \\
\text { mortality } \\
\text { (7) }\end{array}$ \\
\hline ASHA X NREGA X CDD exceeding $90 \mathrm{~F}$ in utero and birth month & & & & & $\begin{array}{l}0.0000277 \\
(0.000343)\end{array}$ & & $\begin{array}{l}-0.0000052 \\
(0.000304)\end{array}$ \\
\hline ASHA X CDD exceeding 90F in utero and birth month & $\begin{array}{c}-0.00377 * * \\
(0.00171)\end{array}$ & & $\begin{array}{c}-0.00430 * * \\
(0.00204)\end{array}$ & $\begin{array}{c}-0.00436 * * \\
(0.00201)\end{array}$ & $\begin{array}{c}-0.00443 * \\
(0.00217)\end{array}$ & $\begin{array}{c}-0.00412 * * \\
(0.00195)\end{array}$ & $\begin{array}{l}-0.00417 * \\
(0.00210)\end{array}$ \\
\hline NREGA X CDD exceeding $90 \mathrm{~F}$ in utero and birth month & & $\begin{array}{l}-0.00170^{*} \\
(0.000898)\end{array}$ & $\begin{array}{c}0.00200 \\
(0.00167)\end{array}$ & $\begin{array}{c}0.00253 \\
(0.00163)\end{array}$ & $\begin{array}{c}0.00240 \\
(0.00227)\end{array}$ & $\begin{array}{c}0.00220 \\
(0.00147)\end{array}$ & $\begin{array}{c}0.00233 \\
(0.00191)\end{array}$ \\
\hline CDD exceeding $90 \mathrm{~F}$ in utero and birth month & $\begin{array}{c}0.0213^{* *} \\
(0.0100)\end{array}$ & $\begin{array}{l}0.0190 * \\
(0.0105)\end{array}$ & $\begin{array}{c}0.0209 * * \\
(0.0101)\end{array}$ & $\begin{array}{l}0.0216^{*} \\
(0.0106)\end{array}$ & $\begin{array}{c}0.0222 * * \\
(0.0104)\end{array}$ & $\begin{array}{c}0.0251 \\
(0.0187)\end{array}$ & $\begin{array}{c}0.0262 \\
(0.0185)\end{array}$ \\
\hline $\begin{array}{l}\text { N } \\
\text { Joint Significance of ASHA and NREGA mitigation variables (Prob > F) }\end{array}$ & 356,205 & 356,205 & $\begin{array}{c}356,205 \\
0.0755\end{array}$ & $\begin{array}{c}356,205 \\
0.1009\end{array}$ & $\begin{array}{c}356,205 \\
0.0681\end{array}$ & $\begin{array}{c}356,205 \\
0.1125\end{array}$ & $\begin{array}{c}356,205 \\
0.0497\end{array}$ \\
\hline $\begin{array}{l}\text { Individual Controls } \\
\text { District-Quarter FE } \\
\text { Quarter-Year FE } \\
\text { Birth Month FE } \\
\text { District-Month FE }\end{array}$ & $\begin{array}{l}\mathrm{Y} \\
\mathrm{Y} \\
\mathrm{Y}\end{array}$ & $\begin{array}{l}\mathrm{Y} \\
\mathrm{Y} \\
\mathrm{Y}\end{array}$ & $\begin{array}{l}\mathrm{Y} \\
\mathrm{Y} \\
\mathrm{Y}\end{array}$ & $\begin{array}{l}\mathrm{Y} \\
\mathrm{Y} \\
\mathrm{Y} \\
\mathrm{Y}\end{array}$ & $\begin{array}{l}\mathrm{Y} \\
\mathrm{Y} \\
\mathrm{Y} \\
\mathrm{Y}\end{array}$ & $\begin{array}{l}\mathrm{Y} \\
\mathrm{Y} \\
\mathrm{Y}\end{array}$ & $\begin{array}{l}\mathrm{Y} \\
\mathrm{Y} \\
\mathrm{Y}\end{array}$ \\
\hline $\begin{array}{l}\text { Only rural sample is considered. The dependent variable in the regression is } 1000 \text { if the } \\
\text { a child, and takes the value } 0 \text { otherwise. The variable NREGA is defined similarly. All r } \\
\text { prior to birth and month of birth, DLHS survey round fixed effects, and state level yearly } \\
\text { in urban area, logarithm of of per capita real net state domestic product (in 2004-05 Rupe } \\
\text { aggregate government expenses excluding public health expenses, logarithm of social exp } \\
\text { controls include DMSP mean night time lights in the year of birth and the preceding y } \\
\text { parental years of schooling in categories, and dummies for religion of the household he } \\
\text { following example: if, say, in district Delhi in July 2005, there are two days when temp } \\
=(100-90)+(95-90)=15 \text {. All standard errors are clustered at the state level. }\end{array}$ & $\begin{array}{l}\text { born child died } \\
\text { egressions incluc } \\
\text { controls includin } \\
\text { es), public healt } \\
\text { enditure excludir } \\
\text { ear in the distric } \\
\text { ad. The sample } \\
\text { erature exceedec }\end{array}$ & $\begin{array}{l}\text { an infant, an } \\
\text { the direct im } \\
\text { number of fe } \\
\text { expenditure } \\
\text { g public healtt } \\
\text { of interview, } \\
\text { includes birth } \\
90 \mathrm{~F} \text {. On one }\end{array}$ & $\begin{array}{l}0 \text { otherwise. A } \\
\text { acts of ASHA } \\
\text { ales per } 1,000 \\
\text { percentage of } s \\
\text { xpenses, and p } \\
\text { ummy for a bo } \\
\text { from } 1998 \text { to } 2 \\
y, \text { it was } 95 \mathrm{~F} \text { at }\end{array}$ & $\begin{array}{l}\text { HA represents } \\
\text { d NREGA, tot } \\
\text { ales, percentag } \\
\text { te GDP, own t } \\
\text { capita real pub } \\
\text { child, dummy } \\
\text { 07. Cumulativ } \\
\text { on the other, }\end{array}$ & $\begin{array}{l}\text { re months of } i \\
\text { rainfall in the } \\
\text { of women lite } \\
\text { revenue as pe } \\
\text { c health expen } \\
\text { or multiple bi } \\
\text { Degree Days } \\
\text { was } 100 \mathrm{~F} \text {, th }\end{array}$ & $\begin{array}{l}\text { itero exposure } \\
\text { strict of intervi } \\
\text { e, percentage o } \\
\text { entage of state } \\
\text { s (in 2004-05 R } \\
\text { s, mother age } \\
\text { DD) > } 90 \mathrm{~F} \text { i } \\
\text { Cumulative De }\end{array}$ & $\begin{array}{l}\text { the program for } \\
\text { from } 9 \text { months } \\
\text { opulation living } \\
\text { DP, logarithm of } \\
\text { ees). Individual } \\
\text { four categories, } \\
\text { lustrated by the } \\
\text { ee Days }>90 \mathrm{~F}\end{array}$ \\
\hline
\end{tabular}


Table A12: Mitigation of heat-induced infant mortality due to total exposure to ASHA and NREGA

\begin{tabular}{|c|c|c|c|c|c|c|c|}
\hline & $\begin{array}{c}\text { Infant } \\
\text { mortality } \\
\text { (1) }\end{array}$ & $\begin{array}{c}\text { Infant } \\
\text { mortality } \\
\text { (2) }\end{array}$ & $\begin{array}{c}\text { Infant } \\
\text { mortality } \\
\text { (3) }\end{array}$ & $\begin{array}{c}\text { Infant } \\
\text { mortality } \\
\text { (4) }\end{array}$ & $\begin{array}{c}\text { Infant } \\
\text { mortality } \\
(5)\end{array}$ & $\begin{array}{c}\text { Infant } \\
\text { mortality } \\
(6)\end{array}$ & $\begin{array}{c}\text { Infant } \\
\text { mortality } \\
\text { (7) }\end{array}$ \\
\hline ASHA X NREGA X CDD exceeding $90 \mathrm{~F}$ textitin utero and birth month & & & & & $\begin{array}{c}0.0000332 \\
(0.0000673)\end{array}$ & & $\begin{array}{c}0.0000247 \\
(0.0000644)\end{array}$ \\
\hline ASHA X CDD exceeding 90F textitin utero and birth month & $\begin{array}{c}-0.00170 * * \\
(0.000758)\end{array}$ & & $\begin{array}{l}-0.00190 * \\
(0.00101)\end{array}$ & $\begin{array}{l}-0.00194 * \\
(0.000978)\end{array}$ & $\begin{array}{l}-0.00200^{*} \\
(0.00109)\end{array}$ & $\begin{array}{c}-0.00180 * \\
(0.000960)\end{array}$ & $\begin{array}{c}-0.00184 * \\
(0.00106)\end{array}$ \\
\hline NREGA X CDD exceeding 90F textitin utero and birth month & & $\begin{array}{c}-0.00153 * * * \\
(0.000544)\end{array}$ & $\begin{array}{c}0.000622 \\
(0.000988)\end{array}$ & $\begin{array}{c}0.000909 \\
(0.000958)\end{array}$ & $\begin{array}{l}0.000303 \\
(0.00134)\end{array}$ & $\begin{array}{c}0.000751 \\
(0.000879)\end{array}$ & $\begin{array}{l}0.000309 \\
(0.00135)\end{array}$ \\
\hline CDD exceeding $90 \mathrm{~F}$ textitin utero and birth month & $\begin{array}{l}0.0216^{* * *} \\
(0.00999)\end{array}$ & $\begin{array}{l}0.0200 * \\
(0.0105)\end{array}$ & $\begin{array}{c}0.0213 * * \\
(0.0101)\end{array}$ & $\begin{array}{c}0.0219 * * \\
(0.0106)\end{array}$ & $\begin{array}{c}0.0223 * * \\
(0.0104)\end{array}$ & $\begin{array}{c}0.0235 \\
(0.0189)\end{array}$ & $\begin{array}{c}0.0243 \\
(0.0187)\end{array}$ \\
\hline $\begin{array}{l}\text { N } \\
\text { Joint Significance of ASHA and NREGA mitigation variables (Prob > F) }\end{array}$ & 356,205 & 356,205 & $\begin{array}{c}356,205 \\
0.0318\end{array}$ & $\begin{array}{c}356,205 \\
0.0568\end{array}$ & $\begin{array}{c}356,205 \\
0.0995\end{array}$ & $\begin{array}{c}356,205 \\
0.0517\end{array}$ & $\begin{array}{c}356,205 \\
0.0892\end{array}$ \\
\hline $\begin{array}{l}\text { Individual Controls } \\
\text { District-Quarter FE } \\
\text { Quarter-Year FE } \\
\text { Birth Month FE } \\
\text { District-Month FE }\end{array}$ & $\begin{array}{l}\mathrm{Y} \\
\mathrm{Y} \\
\mathrm{Y}\end{array}$ & $\begin{array}{l}\mathrm{Y} \\
\mathrm{Y} \\
\mathrm{Y}\end{array}$ & $\begin{array}{l}\mathrm{Y} \\
\mathrm{Y} \\
\mathrm{Y}\end{array}$ & $\begin{array}{l}\mathrm{Y} \\
\mathrm{Y} \\
\mathrm{Y} \\
\mathrm{Y}\end{array}$ & $\begin{array}{l}\mathrm{Y} \\
\mathrm{Y} \\
\mathrm{Y} \\
\mathrm{Y}\end{array}$ & $\begin{array}{l}\mathrm{Y} \\
\mathrm{Y} \\
\mathrm{Y}\end{array}$ & $\begin{array}{l}\mathrm{Y} \\
\mathrm{Y} \\
\mathrm{Y}\end{array}$ \\
\hline $\begin{array}{l}\text { Only rural sample is considered. The dependent variable in the regression is } 1000 \text { if the } \mathrm{b} \\
\text { in a district till a child is one year old, and takes the value } 0 \text { otherwise. The variable } \mathrm{N} \\
\text { district of interview from } 9 \text { months prior to birth and month of birth, DLHS survey roun } \\
\text { literate, percentage of population living in urban area, logarithm of of per capita real net } \\
\text { as percentage of state GDP, logarithm of aggregate government expenses excluding public } \\
\text { expenses (in 2004-05 Rupees). Individual controls include DMSP mean night time lights } \\
\text { births, mother age in four categories, parental years of schooling in categories, and dum } \\
\text { (CDD) }>90 \mathrm{~F} \text { is illustrated by the following example: if, say, in district Delhi in July } 20 \\
\text { Cumulative Degree Days }>90 \mathrm{~F}=(100-90)+(95-90)=15 \text {. All standard errors are }\end{array}$ & $\begin{array}{l}\text { orn child died a } \\
\text { IREGA is defin } \\
\text { d fixed effects, } \\
\text { state domestic } \\
\text { c health expense } \\
\text { in the year of } \\
\text { mies for religio } \\
005 \text {, there are th } \\
\text { clustered at the }\end{array}$ & $\begin{array}{l}\text { an infant, and } 0 \text { or } \\
\text { d similarly. All re } \\
\text { ind state level yea } \\
\text { oduct (in 2004-05 } \\
\text { logarithm of soci } \\
\text { ith and the precec } \\
\text { of the household } \\
\text { days when temp } \\
\text { state level. }\end{array}$ & $\begin{array}{l}\text { therwise. ASHA } \\
\text { egressions includ } \\
\text { rly controls incl } \\
\text { Rupees), public } \\
\text { ial expenditure e } \\
\text { ding year in the } \\
\text { head. The sam } \\
\text { erature exceeded }\end{array}$ & $\begin{array}{l}\text { represents the } \\
\text { le the direct in } \\
\text { uding number } \\
\text { health expen } \\
\text { xcluding publi } \\
\text { district of inter } \\
\text { ple includes bi } \\
90 \mathrm{~F} \text {. On one }\end{array}$ & $\begin{array}{l}\text { onths of expost } \\
\text { cts of ASHA } \\
\text { females per 1, } \\
\text { re as percenta } \\
\text { ealth expenses } \\
\mathrm{w} \text {, dummy for } \\
\text { from } 1998 \text { to } \\
\text {, it was } 95 \mathrm{~F} \text { ar }\end{array}$ & $\begin{array}{l}\text { to the progran } \\
\text { NREGA, tot } \\
\text { males, perce } \\
\text { of state GDP, } \\
\text { ad per capita r } \\
\text { oy child, dum } \\
\text { 07. Cumulati } \\
\text { on the other, it }\end{array}$ & $\begin{array}{l}\text { since it started } \\
\text { rainfall in the } \\
\text { tage of women } \\
w n \text { tax revenue } \\
\text { l public health } \\
\text { ny for multiple } \\
\text { e Degree Days } \\
\text { was } 100 \mathrm{~F} \text {, then }\end{array}$ \\
\hline
\end{tabular}

Table A13: Effect of ASHA on antenatal care

Any antenatal care

Any iron supplementation

$\begin{array}{ccc}\text { ASHA } & 0.130 * * * & 0.201 * * * \\ & (0.0331) & (0.0213) \\ \mathrm{N} & 191,842 & 191,842\end{array}$

Only rural sample is considered. The dependent variable in the regression is 1 if the respondent received any care and 0 otherwise. The controls in the regressions include DMSP mean night time lights in the year of birth and the preceding year in the district of interview, DLHS survey round fixed effects, dummy for a boy child, dummy for multiple births, mother age in four categories, parental years of schooling in categories, dummies for religion of the household head, fixed effects for district, birth quarter-year, and birth month. The sample includes births from 1998 to 2007. ASHA takes the value one if a) the mother is interviewed in a state where ASHA is implemented; and b) the child is born in 2005 or later. All standard errors are clustered at the state level. 
Table A14: Effect of ASHA on postnatal care

\begin{tabular}{|c|c|c|c|c|c|}
\hline & BCG (=1) & Measles (=1) & $\begin{array}{c}\text { Number of } \\
\text { polio vaccines }\end{array}$ & $\begin{array}{c}\text { Number of } \\
\text { DPT injections }\end{array}$ & $\begin{array}{c}\text { Number of } \\
\text { Vitamin A doses }\end{array}$ \\
\hline ASHA (=1) & $\begin{array}{c}0.0812 * * * \\
(0.0171)\end{array}$ & $\begin{array}{c}0.0883 * * * \\
(0.0193)\end{array}$ & $\begin{array}{c}0.0262 \\
(0.0386)\end{array}$ & $\begin{array}{c}0.0300 \\
(0.0202)\end{array}$ & $\begin{array}{c}0.137 \\
(0.0810)\end{array}$ \\
\hline $\mathrm{N}$ & 161,848 & 152,138 & 141,682 & 130,033 & 95,061 \\
\hline Mean of dependent variable & 0.88 & 0.74 & 2.69 & 2.66 & 1.89 \\
\hline \multicolumn{6}{|c|}{$\begin{array}{l}\text { Only rural sample is considered. The controls in the regressions include DMSP mean night time lights in the year of birth and the preceding } \\
\text { year in the district of interview, DLHS survey round fixed effects, dummy for a boy child, dummy for multiple births, mother age in four } \\
\text { categories, parental years of schooling in categories, dummies for religion of the household head, fixed effects for birth month, birth year, and } \\
\text { district. The sample includes births from } 1998 \text { to 2007. ASHA takes the value one if a) the mother is interviewed in a state where ASHA is } \\
\text { implemented; and b) the child is born in } 2005 \text { or later. DPT injections include injections for Diphtheria, Whooping Cough, and Tetanus. All } \\
\text { standard errors are clustered at the state level. }\end{array}$} \\
\hline
\end{tabular}

Table A15: Effect of ASHA on health information dissemination

\begin{tabular}{|c|c|c|c|}
\hline & $\begin{array}{l}\text { No knowledge of danger signs } \\
\text { for diarrhea } \\
\text { (1) }\end{array}$ & $\begin{array}{l}\text { No knowledge of danger signs } \\
\text { for pneumonia } \\
\text { (2) }\end{array}$ & $\begin{array}{c}\text { Advice from health worker } \\
\text { about diarrhea or pneumonia } \\
\text { (3) }\end{array}$ \\
\hline ASHA & $\begin{array}{c}-0.0210 \\
(0.0592)\end{array}$ & $\begin{array}{c}-0.400 * * * \\
(0.137)\end{array}$ & $\begin{array}{c}0.0703 * * \\
(0.0291)\end{array}$ \\
\hline
\end{tabular}


Table A16: Implementation of different government schemes

\begin{tabular}{|c|c|c|c|c|c|c|c|c|c|c|c|}
\hline & \multirow{2}{*}{ ASHA } & \multicolumn{2}{|c|}{ Child and Maternal Health } & \multicolumn{2}{|c|}{ Water and Sanitation } & \multicolumn{3}{|c|}{ Employment Programs } & \multirow[b]{2}{*}{ JRY } & \multicolumn{2}{|c|}{ Others } \\
\hline & & JSY & ICDS & SP & RGNDWM & NFFWP & NREP & PMRY & & IAY & JGSY \\
\hline High Focus States & $\begin{array}{c}0.483^{* * *} \\
(0.0242)\end{array}$ & $\begin{array}{c}-0.0533^{* * *} * \\
(0.0148)\end{array}$ & $\begin{array}{c}-0.0348 * * * \\
(0.0133)\end{array}$ & $\begin{array}{c}-0.275^{*} * * \\
(0.0195)\end{array}$ & $\begin{array}{c}0.0119 \\
(0.0130)\end{array}$ & $\begin{array}{c}-0.0363^{* *} * \\
(0.0167)\end{array}$ & $\begin{array}{c}-0.000699 \\
(0.0167)\end{array}$ & $\begin{array}{c}0.0434 * * * \\
(0.0156)\end{array}$ & $\begin{array}{c}0.0240 \\
(0.0163)\end{array}$ & $\begin{array}{c}-0.0774 * * * \\
(0.0188)\end{array}$ & $\begin{array}{c}-0.0415 \text { *** } \\
(0.00997)\end{array}$ \\
\hline Mean of dependent variable & $60 \%$ & $82 \%$ & $84 \%$ & $32 \%$ & $16 \%$ & $23 \%$ & $31 \%$ & $35 \%$ & $28 \%$ & $75 \%$ & $10 \%$ \\
\hline $\mathrm{N}$ & 22,209 & 22,209 & 22,209 & 22,209 & 22,209 & 22,209 & 22,209 & 22,209 & 22,209 & 22,209 & 22,209 \\
\hline
\end{tabular}

The dependent variables take the value 1 if a village has the program, during the third wave of DLHS survey, and zero otherwise. Child and Maternal Health programs considered are Janani Suraksha Yojana (JSY), and Integrated Child Development Scheme (ICDS); Water and Sanitation programs include Sanitation Programme (SP), and Rajiv Gandhi National Drinking Water Mission (RGNDWM); Employment programs include National Food for Work Programme (NFFWP), National Rural Employment Programme (NREP), Prime Minister Rojgar Yojana (PMRY), and Jawahar Rozgar Yojana (JRY); and Others include Indira Awas Yaojna (IAY), and Jawahar Gram Samridhi Yojana (JGSY). High Focus states are the states in which the ASHA program was heavily implemented between 2005 and 2008 . Please refer to the main text for additional details. All regressions control for logarithm of households in a village, dummies for the following: if there is a bus station in the village, if the village has all weather roads, if piped water is the main source of drinking water in the village, if the village has electricity, if the village has no bus-station, if the village is not close to a town, if there is a health sub-center in the village, if the village has a phone booth with national calling facility, if the primary health center provides round the clock service in the village, and if there is a market in the village. All the standard errors are clustered at the district level.

Table A17: Trend break estimates of the effect of ASHA on heat-induced infant mortality

Year-event time

(1)
Month-event time

(2)

$\begin{array}{lcc}\text { Policy }\left(\eta_{1}\right) & -0.0774 * * & -0.0394 \\ & (0.0273) & (0.0318) \\ \text { Trend }\left(\eta_{2}\right) & 0.00646^{*} & 0.000891 \\ & (0.00317) & (0.00334)\end{array}$

$\mathrm{N}$

10

17

The first and second columns show the estimation results for regressing the estimates reported in Figure A4 and Figure A6 respectively on an indicator variable for whether the policy is in force and a linear trend. The indicator variable in column 1 takes the value one if the event time corresponds to 2005 or more on the event time axis (refer to Figure A4), and zero otherwise. The indicator variable in column 2 takes the value one if the event time corresponds to 10 to 12 months after birth or to the left of 10 to 12 months after birth on the event time axis (refer to Figure A6). The trend is defined for each column according to the respective event time axes. See the text for further details. 
Table A18: Trend break estimates of the effect of NREGA on heat-induced infant mortality

\begin{tabular}{|c|c|c|}
\hline & $\begin{array}{c}\text { Year-event time } \\
\text { (1) }\end{array}$ & $\begin{array}{c}\text { Month-event time } \\
\text { (2) }\end{array}$ \\
\hline Policy $\left(\xi_{1}\right)$ & $\begin{array}{l}0.00785 \\
(0.0112)\end{array}$ & $\begin{array}{l}0.00393 \\
(0.0271)\end{array}$ \\
\hline Trend $\left(\xi_{2}\right)$ & $\begin{array}{l}-0.00347 * \\
(0.00153)\end{array}$ & $\begin{array}{l}-0.00253 \\
(0.00248)\end{array}$ \\
\hline $\mathbf{N}$ & 12 & 16 \\
\hline \multicolumn{3}{|c|}{$\begin{array}{l}\text { The first and second columns show the estimation results for regressing } \\
\text { the estimates reported in Figure A5 and Figure A7 respectively on an } \\
\text { indicator variable for whether the policy is in force and a linear trend. } \\
\text { The indicator variable in column } 1 \text { takes the value one if the event time } \\
\text { takes the values zero or less on the event time axis (refer to Figure A5), } \\
\text { and zero otherwise. The indicator variable in column } 2 \text { takes the value } \\
\text { one if the event time corresponds to } 10 \text { to } 12 \text { months after birth or to } \\
\text { the left of } 10 \text { to } 12 \text { months after birth on the event time axis (refer to } \\
\text { Figure A7). The trend is defined for each column according to the re- } \\
\text { spective event time axes. See the text for further details. }\end{array}$} \\
\hline
\end{tabular}


Table A19: Structural break analysis

\begin{tabular}{|c|c|c|}
\hline & $\begin{array}{c}\text { Time of } \\
\text { maximum } F \\
\text { (1) }\end{array}$ & $\begin{array}{c}\text { QLR } \\
\text { test statistic } \\
(2)\end{array}$ \\
\hline \multicolumn{3}{|l|}{ Panel A: ASHA } \\
\hline Year-event time & Year of ASHA implementation & 8.03 \\
\hline Month-event time & ASHA implemented 10 to 12 months after birth & 1.54 \\
\hline \multicolumn{3}{|l|}{ Panel B: NREGA } \\
\hline Year-event time & NREGA implemented 4 years after birth & 2.92 \\
\hline Month-event time & NREGA implemented 4 to 6 months after birth & 13.49 \\
\hline
\end{tabular}

Following the approach in Greenstone and Hanna (2014), here we do the trend break exercise repeatedly by redefining a new policy implementation date each time and the $F$-statistic associated with the null hypothesis that the policy is not effective. The first column reports the date at which the $F$-statistic is maximum while the second column reports this maximum $F$-value. For ASHA, we examine from year 2000 to 2006 and event time 16-18 months before birth to 22-27 months after birth for the year-event time and month-event time event study estimates respectively as possible break dates. For NREGA, we examine from year 0 to 7 years after birth and 13-15 months before birth to 22-27 months after birth for the yearevent time and month-event time event study estimates respectively as possible break dates. See the text for further details. 